

\section{Sumário}

I. Crônicas do Direito Internacional .................................................1

AMAZONIE: LE DROIT INTERNATIONAL EN VIGUEUR APPORTE DES RÉPONSES SUBSTANTIELLES ... 3 Pierre-Marie Dupuy

A eVOluÇão da SOluÇão DE CONTROVÉRSias NOS ACFIs 8 Ana Rachel Freitas da Silva

II. Dossiê Especial: Direito ambientai 14

A brief overview of Sustainable DeVelopment: HOW A DEBATEd CONCEPT With A MUCH-CONTESTED LEGAL NATURE COULD PERFORM A VALUABLE ROLE IN THE DECISION-MAKING ......16 Natali Francine Cinelli Moreira

A meta 11 de Aichi e as Áreas marinhas protegidas em grande ESCALA: proteção ambienTAL OU OPORTUNISMO POLÍTICO?

Alexandre Pereira da Silva

LITIGÂNCIA CLIMÁTICA COMO ESTRATÉGIA JURISDICIONAL AO AQUECIMENTO GLOBAL ANTROPOGÊNICO E MUDANÇAS CLIMÁTICAS

Délton Winter de Carvalho e Kelly de Souza Barbosa

AsSESSMENT AND CHALlENGES OF CARBON MARKETS

Louise Pigeolet e Arnaud Van Waeyenberge

As abordagens dos países da América Latina e Caribe sobre a mobilidade humana proVOCADA PELAS MUDANÇAS CLIMÁTICAS

Diogo Andreola Serraglio e Heline Sivini Ferreira

Implementation of Legal mechanisms of environmental protection by the South PaCIFIC REGIONAL ORGANIZATIONS 116 Joanna Siekiera 
CONCILIATING THE OVERLAP OF PROTECTED AREAS AND TRADITIONAL TERRITORIES: LEGAL INNOVATIONS FOR BIOLOGICAL DIVERSITY CONSERVATION IN BRAZILIAN PARKS

Nathalia Fernandes Lima e Solange Teles Silva

O USO DE DRONES COMO INSTRUMENTO PARA A CONSERVAÇÃo DA BIODIVERSIDADE NO BRASIL141 Larissa Suassuna Carvalho Barros e Marcia Dieguez Leuzinger

Agrotóxicos e direitos humanos no contexto global: o Brasil EM Risco de Retrocesso?

Marcelo Pretto Mosmann, Letícia Albuquerque e Isabele Bruna Barbieri

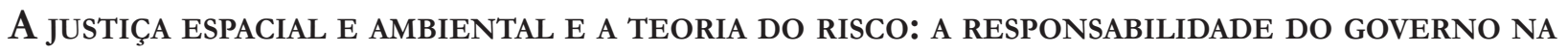
PREVENÇÃo CONTRA DESASTRES (NO BRASIL). 169

José Adércio Leite Sampaio e Edson Rodrigues de Oliveira

The judgment of the case Xucuru People v. Brazil: Inter-American Court of Human RigHTS BETWEEN CONSOLIDATION AND SETBACKS

Gabriela Cristina Braga Navarro

II. Artigos sobre outros temas

NACIONALIDADE: NOVAS REGRAS, VELHOS PROBLEMAS

226

Paulo Henrique Faria Nunes

O EXERCíCIO DA JURISDIÇÃO INTERAMERICANA DE DIREITOS HUMANOS: LEGITIMIDADE, PROBLEMAS E POSSÍVEIS SOLUÇÕES

Felipe Grizotto Ferreira, Guilherme Perez Cabrale Lucas Catib de Laurentiis

A proteção da identidade de gênero na jurisprudênCia da Corte Europeia de Direitos Humanos

Gabriel Coutinho Galil

O COMITÊ JURÍdico INTERAMERICANO dA OEA E A CODIFICAÇÃo DO DIREITO INTERNACIONAL REGIONAL. 
O caso Petruhhin e o princípio do nível mais elevado de proteção no tocante aos diREITOS FUNDAMENTAIS NO ÂMBITO DA UNIÃo EUROPEIA............................................304

Clovis Demarchi e Jaine Cristina Suzin

A AUTONOMia da VONTADE NA ESCOLHA dA LEI APLICÁVEl AOS CONTRATOS DE COMÉRCiO INTER-

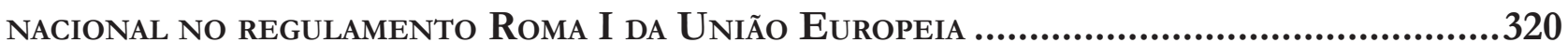

Aline Beltrame de Moura e Rafaela Hörmann

A JuRisdição da ICANN: desafios atuais e Prospectivas futuras...............................335 Aziz Tuffi Saliba e Amael Notini Moreira Bahia

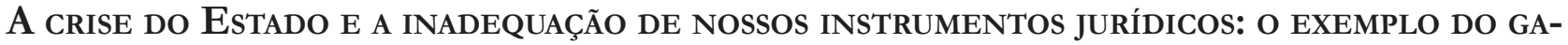
RANTISMO PENAL NO BRASIL.

Oswaldo Poll Costa e Francisco Quintanilha Veras Neto

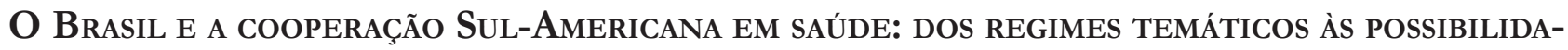
DES DE EFETIVAÇÃo ESTRUTURANTE

Ademar Pozzatti Junior e Luiza Witzel Farias

III. RESENHAS

Resenha da obra: SILVA, Waldimeiry Correa da. Regime internacional de enfrentaMENTO AO TRÁFICO DE PESSOAS: AVANÇOS E DESAFIOS PARA A PROTEÇÃo DOS DIREITOS HUMANOS. Rio de Janeiro: Lumen Juris, 2018. 385

Mércia Cardoso de Souza e Guirino Nhatave 


\title{
As abordagens dos países da América Latina e Caribe sobre a mobilidade humana provocada pelas mudanças climáticas*
}

\author{
Latin America and Caribbean countries' \\ approaches on human mobility caused by \\ climate change
}

* Recebido em 17/07/2019

Aprovado em 04/09/2019

** Pós-Doutorando em Direito na Deutsches Institut für Entwicklungspolitik (DIE) por meio de bolsa da Alexander von Humboldt Foundation. Doutor em Direito Socioambiental e Sustentabilidade pela Pontifícia Universidade Católica do Paraná (PUCPR), tendo realizado seu estágio de doutoramento na Elisabeth Haub School of Law - Pace University, em White Plains, EUA (setembro 2017 - maio 2018) e na United Nations University - Environment and Human Security (UNU-EHS), em Bonn, Alemanha (Março - Junho 2017). Mestre em Direito pela PUCPR. Pós-graduado em Direito Ambiental pela Universidade Federal do Paraná (UFPR). Especialista em Direito Internacional do Meio Ambiente pela United Nations Institute for Training and Research (UNITAR); Graduado em Direito pelo Centro Universitário Curitiba (UNICURITIBA). Membro pesquisador da Comissão Mundial de Direito Ambiental da International Union for Conservation of $\mathrm{Na}$ ture (IUCN) e da Rede Sul-Americana para as Migrações Ambientais (RESAMA). Advogado. E-mail: diogo.aserraglio@gmail.com

*** Doutora em Direito pela Universidade Federal de Santa Catarina (UFSC), tendo realizado seu estágio de doutoramento no Centre for Environmental Law, da Macquarie University, em Sidney, Austrália. Mestre em Direito pela UFSC. Graduada em Direito pela Universidade Estadual da Paraíba (UEPB). Professora Adjunta do Curso de Graduação e do Programa de Pós-Graduação em Direito da Pontifícia Universidade Católica do Paraná (PUCPR). Pesquisadora do Grupo de Pesquisa Direito Ambiental e Ecologia Política na Sociedade de Risco (UFSC) e do Grupo de Pesquisa Meio Ambiente: Sociedades Tradicionais e Sociedade Hegemônica (PUCPR). Diretora de Assuntos Internacionais do Instituto O Direito por um Planeta Verde (IDPV). Coordenadora Regional da Associação dos Professores de Direito Ambiental do Brasil (APRODAB-Sul). Membro da Commission on Environmental Law da International Union for Conservation of Nature (IUCN). Curitiba, Paraná, Brasil. E-mail: hsivini@yahoo.com.br

\author{
Diogo Andreola Serraglio** \\ Heline Sivini Ferreira***
}

\section{Resumo}

O presente estudo visa examinar em que medida os países que compõem a América Latina e o Caribe vem integrando a mobilidade humana no contexto dos efeitos adversos das mudanças climáticas às suas políticas públicas. Para tanto, fazendo-se uso do método de abordagem dedutivo e da revisão bibliográfica como técnica de pesquisa, buscou-se, inicialmente, compreender a mobilidade humana com base na ocorrência de adversidades ambientais, particularmente do aquecimento do sistema climático global. Na sequência, analisou-se os fluxos migratórios sob a perspectiva do regime climático internacional, com enfoque nas disposições que sucederam o Acordo de Paris e culminaram no estabelecimento da Força-Tarefa sobre Deslocamento, por meio do Mecanismo Internacional de Varsóvia sobre Perdas e Danos. Por fim, considerou-se a mobilidade humana no contexto das políticas públicas climáticas dos países latino-americanos e caribenhos. Nessa oportunidade, além dos Planos Nacionais de Adaptação (PNAs) e das Contribuições Nacionalmente Determinadas (CNDs), estudou-se a legislação nacional que regulamenta a mitigação e a adaptação às mudanças do clima no âmbito interno dos 34 países que compõem a região. Não obstante o reconhecimento da urgência que o tema encerra, são poucos os países que abordam a mobilidade humana em suas políticas públicas, indicando que os instrumentos jurídicos estabelecidos até o momento não são suficientemente aproveitados e/ou explorados. Diante da inexistência de mecanismos que permitam o enfrentamento adequado da questão, comunidades inteiras permanecem com a dignidade da pessoa humana ameaçada.

Palavras-chave: Mudanças climáticas. Mobilidade humana. Regime climático internacional. Políticas Públicas. América Latina e Caribe.

\section{Abstract}

The study aims at examining to what extent Latin American and Caribbean countries have integrated buman mobility in the context of the adverse effects of climate change and related topics in their policies. For this purpose, through de- 
ductive research approach and literature review, human mobility patterns related to environmental misfortunes in contemporary society, especially the ones associated with global warming, are initially understood. Likewise, the topic is then analyzed from the international climate regime, with focus on the provisions that followed the Paris Agreement and resulted in the establishment of the Task-Force on Displacement, through the Warsaw International Mechanism on Loss and Damage. Finally, it is intended to evaluate climate change-related policies in Latin American and Caribbean countries. Thus, in addition to the National Adaptation Plans (NAPs) and Nationally Determined Contributions (NDCs), national legislation regulating climate change mitigation and adaptation within the 34 countries of the region were studied. Notwithstanding the acknowledgment of the urgency of the topic, only few countries address human mobility in their policies thus far, indicating that the legal instruments established are not sufficiently harnessed. Given the lack of specific mechanisms, communities remain with their human dignity at risk.

Keywords: Climate change. Human mobility. International climate regime. Policies. Latin America and the Caribbean.

\section{Introdução}

As mudanças climáticas decorrentes do aquecimento global deixaram de ser uma questão meramente ambiental, também ganhando destaque em razão das suas implicações econômicas, políticas e sociais. Essas acabam por acentuar desigualdades e injustiças em inúmeras regiões do globo, como a América Latina e o Caribe. A variabilidade dos padrões climáticos nessas localidades do continente americano, os contrastes socioeconômicos, a falta de capacidade adaptativa, bem como o alto grau de vulnerabilidade, expõem comunidades inteiras aos seus efeitos adversos, obrigando-as, às vezes, a abandonar seus locais de residência habitual.

A relevância do estudo das relações existentes entre fluxos populacionais forçados por razões ambientais mostra-se evidente, principalmente sob a perspectiva das mudanças climáticas decorrentes do aquecimento global, as quais têm intensificado a incidência e a recorrência de infortúnios ao redor do globo. Ainda que ninguém se desloque por um único motivo e as pesquisas sobre o tema apresentem dificuldades em decodificar todas as particularidades que se conjugam às causas ambientais para compelir o movimento de pessoas, os riscos a que se submetem diversos aglomerados humanos exigem respostas eficazes da sociedade contemporânea.

À vista disso, objetiva-se examinar em que medida os países que compõem a América Latina e o Caribe integram a mobilidade bumana no contexto dos efeitos adversos das mudanças do clima em suas políticas públicas de cunho climático, contribuindo para a redução, prevenção e melhor gerenciamento dos deslocamentos desse gênero em âmbito regional.

Por meio do método dedutivo, busca-se, inicialmente, a contextualização da temática: além da multicausalidade dos processos migratórios, os dados disponibilizados pelo Centro de Monitoramento de Deslocamento Interno (IDMC) e a multiplicidade de nomenclatura utilizadas para descrever aqueles que se deslocam em razão dos efeitos adversos das mudanças climáticas são analisados.

$\mathrm{Na}$ sequência, avalia-se o aparato normativo que aborda a mobilidade humana no regime climático internacional, com especial enfoque para disposições das Conferências das Partes (COPs) que sucederam o Acordo de Paris, em 2015, e culminaram na instituição do Mecanismo Internacional de Varsóvia sobre Perdas e Danos (WIM) e no estabelecimento da Força-Tarefa sobre Deslocamento (TFD).

Por fim, as políticas públicas de cunho climático dos países latino-americanos e caribenhos são investigadas com o intuito de verificar em que medida as conexões entre mudanças climáticas e mobilidade humana vêm sendo incorporadas e assimiladas pelas agendas nacionais. Para tanto, os Planos Nacionais de Adaptação (PNAs) e as Contribuicoões Nacionalmente Determinadas (NDCs) submetidas ao sistema da Convenção-Quadro das Nações Unidas sobre Mudança Climática (CQNUMC) até o momento, assim como as legislações nacionais que regulamentam a mitigação e a adaptação às mudanças do clima em âmbito interno dos 34 países da região foram devidamente esmiuçados.

Verifica-se, em que grau a região encontra-se alinhada e em consonância com as diretrizes e recomendações internacionais que abordam o tema, possibilitando, também, a identificação de lacunas e inconsistências. Em verdade, a complexidade dos processos migratórios na atualidade impõe a reconsideração das bases que estruturam os instrumentos normativos existentes com 
o intuito de captar os novos desafios da mobilidade humana, respondendo às demandas dos movimentos desencadeados por adversidades de cunho climático. Sem essa estrutura jurídica, as lacunas que permeiam a problemática têm o potencial de exacerbar crises humanitárias e instabilidades políticas.

\section{A mobilidade humana a partir dos efeitos adversos das mudanças climáticas}

A mobilidade humana por motivos ambientais opera em uma diversidade de escalas de tempo e espaço, não sendo um fato inédito na história ${ }^{1}$. Deslocamentos não ocorrem somente diante de fenômenos que se desdobram ao longo de décadas ou até mesmo séculos para modificar a habitabilidade de uma determinada região, como as oscilações naturais do clima em razão de períodos geológicos; acontecem também em face de atividades geofísicas próprias do sistema terrestre, assim como da interferência antropogênica no meio ambiente. Além de alterar as condições de sobrevivência, tais transformações sempre desafiaram a adaptação de aglomerados humanos em novas localidades².

O acelerado processo de desenvolvimento em busca de maior crescimento econômico, apesar de ter possibilitado a expansão da capacidade de produção, armazenamento e circulação de bens de consumo, tem sido, em grande medida, responsável pela alteração dos padrões climáticos. Em verdade, a queima desenfreada de combustíveis fósseis e a consequente emissão de gases de efeito estufa (GEE) na atmosfera tem contribuído de forma significativa para o aquecimento global. Como consequência do aumento da temperatura do sistema climático, houve também a modificação e a intensificação de processos migratórios ${ }^{3}$.

À vista disso, considerando a variedade de abordagens jurídicas que circundam o tema, além de delimi-

HETHERINGTON, Renée. Living in a dangerous climate: climate change and human evolution. Nova Iorque, EUA: Cambridge University Press, 2012. p. 13.

2 MCLEMAN, Robert A. Climate and buman migration: past experiences, future challenges. Nova Iorque, EUA: Cambridge University Press, 2014. p. 15.

3 BRADBROOK, Adrian J.; OT'TINGER, Richard L. Energy law and sustainable development. Geneva, Switzerland: IUCN, 2003. p. 1314. tar algumas das particularidades que permitem a melhor compreensão dos fluxos populacionais de cunho climático, o presente tópico relaciona o fenômeno aos preceitos do regime climático internacional contemporâneo no intento de facilitar a identificação de respostas eficazes.

\subsection{Compreendendo os fluxos populacionais que decorrem das alterações induzidas do clima}

Apesar do Primeiro Relatório de Avaliação (AR1) do Painel Intergovernamental sobre Mudanças Climáticas (IPCC), publicado em 1990, ter sido categórico ao afirmar que "[...] um dos efeitos mais graves das mudanças climáticas poderia ser a migração forçada de milhares de pessoas em razão da erosão e de inundações costeiras, assim como de secas severas" ", esse tema só voltou a ser mencionado pelo IPCC em 2014, quando da publicação do Quinto Relatório de Avaliação (AR5). De acordo com o AR5, no período compreendido entre os anos de 1951 e 2010, houve uma elevação da temperatura média global entre $0.5^{\circ} \mathrm{C}$ e $1.3^{\circ} \mathrm{C}$. Diante desse aumento, cujas causas são reconhecidamente antropogênicas, estimou-se que haveria o deslocamento de um maior número de pessoas, sobretudo daquelas expostas a eventos climáticos extremos nos países em desenvolvimento ${ }^{5}$.

Em outubro de 2018, o IPCC divulgou o relatório especial Aquecimento Global de 1,50 C (SR15) ${ }^{6}$. No que tange especificamente à mobilidade humana, o documento ressaltou a dificuldade de se estabelecer um nexo de causalidade entre os efeitos das alterações induzidas do clima e os processos de migração. Isso porque, na

4 INTERGOVERNMENTAL PANEL ON CLIMATE CHANGE. Climate change: The 1990 and 1992 IPCC Assessments. IPCC First Assessment Report Overview and Policymaker Summaries and 1992 IPCC Supplement. Canada, 1990. p. 103. Traduzido a partir de: "[...] the gravest effects of climate change may be those on buman migration as millions are displaced by shoreline erosion, coastal flooding and severe drought."

INTERGOVERNMENTAL PANEL ON CLIMATE CHANGE. Working Group I Contribution To The IPCC Fifth Assessment Report. Climate Change 2013: the Physical Science Basis. Sweden: 2013. p. 16.

6 INTERGOVERNMENTAL PANEL ON CLIMATE CHANGE. Global Warming of $1,5^{\circ} \mathrm{C}$ : an IPCC special report on the impacts of global warming of $1,5^{\circ} \mathrm{C}$ above pre-industrial levels and related global greenhouse gas emission pathways, in the context of strengthening the global response to the threat of climate change, sustainable development, and efforts to eradicate poverty. República da Coréia: Summary for Policymakers, 2018. p. 04. 
maioria dos casos, esses complexos processos decorrem de fatores múltiplos, inviabilizando um vínculo isolado. Diante disso, percebe-se que as mudanças climáticas não podem ser apontadas como causa única de fluxos populacionais ${ }^{7}$. Ainda que o desequilíbrio do sistema climático possa operar como um gatilho, as motivações que ensejam a mobilidade humana são, via de regra, interdependentes, evidenciando a combinação de fatores que se agravam mutuamente ${ }^{8}$.

À vista disso, abordar a mobilidade humana no contexto das mudanças climáticas vai além da análise de como indivíduos reagem aos seus efeitos adversos. Há de se falar na melhor compreensão dos desafios que raramente são definidos como climáticos ou, ainda, relacionados a outros infortúnios ambientais?. Revela-se, diante disso, que "a complexidade das decisões de migrar [...] torna quase que impossível o fornecimento de estimativas precisas das pessoas que se movem apenas por conta das mudanças climáticas” ${ }^{\prime 10}$.

As primeiras estimativas vinculando fluxos populacionais a adversidades ambientais resultaram dos prognósticos de Norman Myers ${ }^{11}$. Na obra Environmental Exodus: An Emergent Crisis in the Global Arena, publicada em 1995, o autor destaca que, naquele ano, o número total de deslocados por questões ambientais somava pelo menos 25 milhões de indivíduos, ao passo que os chamados refugiados tradicionais ${ }^{12}$ totalizavam não mais que 27 milhões de pessoas ${ }^{13}$. Dez anos mais tarde, ao

MCADAM, Jane. Climate change, forced migration and international law. Oxford, UK: Oxford University Press, 2012. p. 20.

8 RAMOS, Erika Pires. Refugiados, migrantes ou deslocados ambientais: uma abordagem inspirada na proteção do meio ambiente e nos direitos humanos. In: LEITE, José Rubens Morato (coord.). Manual de direito ambiental. São Paulo: Saraiva, 2015. p. 750.

9 HASTRUP, Kirsten; OLWIG, Karen F. Introduction: Climate change and human mobility. In: HASTRUP, Kirsten; OLWIG, Karen F. Climate change and human mobility: Global Challenges to the Social Sciences. Londres, UK: Cambridge University Press, 2012. p. 03. 10 MCADAM, Jane. Climate change, forced migration and international law. Oxford, UK: Oxford University Press, 2012. p. 5. Traduzido a partir de: "The complexity of migration decisions [...] make it virtually impossible to provide an accurate estimate of people who move because of climate change."

11 MAYER, Benoit. Who are 'climate refugees? Academic engagement in the post-truth era. In: BEHRMAN, Simon; KENT, Avidan. Climate Refugees: beyond the Legal Impasse? EUA: Routledge Studies in Environmental Migration, Displacement and Resettlement, 2018. p. 92.

12 O termo refugiado encontra-se definido no $\$ 2^{\circ}$ do artigo $1^{\circ}$ da Convenção das Nações Unidas Relativa ao Estatuto dos Refugiados de 1951.

13 MYERS, Norman. Environmental exodus: an emergent crisis in the concluir que a questão poderia servir "como poderoso fundamento para a adoção de medidas voltadas ao refreamento do aquecimento global"14, Myers afirmou que a quantidade de indivíduos obrigados a migrar de sua terra natal em razão de infortúnios ambientais, incluindo os que decorrem das alterações induzidas do clima, poderia alcançar 200 milhões até $2050^{15}$. Tais dados foram citados por meios de comunicação, organizações não governamentais (ONGs) e documentos oficiais, fazendo com que o tema despontasse nos debates públicos $^{16}$.

$\mathrm{Na}$ atualidade, são os dados do Centro de Monitoramento de Deslocamento Interno (IDMC) que merecem destaque $^{17}$. Em seu último relatório, intitulado 2019 Global Report on Internal Displacement (GRID), veiculado em maio de 2019, o IDMC aponta que, no período compreendido entre 2008 e 2018, uma média anual de 7.4 milhões de indivíduos tornaram-se deslocados internos em razão de conflitos armados e 24 milhões em virtude da iminência de desastres de cunho ambiental. Somente em 2018, 28 milhões de novos deslocamentos no interior de fronteiras nacionais foram registrados em 148 países: 10.8 milhões decorreram de conflagrações e 17.2

global arena. Washington: Project of the Climate Institute, 1995. p. 1. 14 MAYER, Benoît. Who are 'climate refugees? Academic engagement in the post-truth era. In: BEHRMAN, Simon; KENT, Avidan. Climate Refugees: beyond the Legal Impasse? EUA: Routledge Studies in Environmental Migration, Displacement and Resettlement, 2018. p. 92.

15 MYERS, Norman. Environmental refugees: an emergent security issue. Praga: Oxford University, U.K., 2005. p. 23.

16 Vale mencionar que, em alguns casos, as estimativas têm sido manipuladas com o intuito de chamar a atenção para o assunto, justificar a adoção de medidas que permitam o fechamento de fronteiras nacionais, ou possibilitar a aquisição de auxílio financeiro para projetos de adaptação. Como consequência, não é de se surpreender que essas conjecturas sejam ainda imprecisas. Ainda que todas as previsões tenham tido um impacto duradouro nos debates públicos que versam sobre a chamada migração ambiental, elas não foram fundamentadas em métodos científicos robustos e várias de suas questões ainda permanecem sem repostas, o que dificulta sobremaneira a adoção de medidas que possam suavizar ou contornar o problema de forma adequada. NICHOLSON, Calum T. M. Climate-induced migration: ways forward in the face of an intrinsically equivocal concept. In: MAYER, Benoit; CRÉPEAU, François. Research Handbook on Climate Change, Migration and the Law. Cheltenham, UK: Edward Elgar Publishing, 2017. p. 51.

17 Estabelecido pelo Conselho Norueguês para Refugiados (CNR), os dados produzidos pela organização não governamental não incluem deslocamentos que resultam de eventos de início lento, ou seja, processos que se desenrolam de forma gradativa - no decorrer de anos ou até mesmo décadas —, tampouco contabilizam o deslocamento de pessoas que ocorre para além de suas fronteiras nacionais. 
milhões derivaram de infortúnios ambientais ${ }^{18}$. Isso significa que $61 \%$ de todo o fluxo populacional interno e forçado do ano em tela teve uma adversidade ambiental como estopim. Desse montante, apenas 1.1 milhões de habitantes foram obrigados a abandonar suas residências em consequência de atividades geofísicas: 915.000 em razão de terremotos e 186.000 por conta de erupções vulcânicas ${ }^{19}$.

Nesse contexto, os deslocamentos registrados no ano de 2018 foram desencadeados, sobretudo, por circunstâncias climatológicas: 5.4 milhões de pessoas foram removidas em razão de inundações e transbordamentos de corpos d'água; 9.3 milhões em razão de ciclones tropicais e tempestades de menor intensidade; $764.000 \mathrm{em}$ virtude de períodos de estiagem prolongados; 424.000 por força de incêndios; 165.000 por efeito de deslizamentos de terras; e 24.000 por conta de ondas de calor ${ }^{20}$.

O continente americano, dentro do qual se delimita o foco desta pesquisa, foi responsável por $9.8 \%$ dos deslocamentos oriundos de desastres. É dizer, aproximadamente 1.7 milhões de pessoas foram forçadas a migrar dentro de suas fronteiras nacionais em decorrência de adversidades ambientais nas Américas ao longo de 2018. Esse número é cerca de quatro vezes maior que os 404.000 indivíduos que fugiram de conflitos armados $^{21}$. Apesar da incidência de períodos prolongados de estiagem e de inundações, foram os ciclones tropicais que geraram boa parcela dos fluxos populacionais associados a desastres na região ${ }^{22}$.

Dito isso, deve-se considerar que as discussões so-

18 INTERNAL DISPLACEMENT MONITORING CENTRE. 2019 Global Report on Internal Displacement (GRID 2019). Genebra, Suíça: IDMC/NRC, 2019. p. 2.

19 INTERNAL DISPLACEMENT MONITORING CENTRE. 2019 Global Report on Internal Displacement (GRID 2019). Genebra, Suíça: IDMC/NRC, 2019. p. 7.

20 INTERNAL DISPLACEMENT MONITORING CENTRE. 2019 Global Report on Internal Displacement (GRID 2019). Genebra, Suíça: IDMC/NRC, 2019. p. 7.

${ }^{21}$ Dentre os cinco países com o maior número de novos deslocamentos - tanto por conflitos armados quanto por adversidades ambientais - em 2018, estão: Estados Unidos da América (EUA), com 1.247.000 pessoas; El Salvador, com 250.700 indivíduos; Colômbia, com 212.000 habitantes; Brasil, com 86.000 cidadãos; e Cuba, com 52.000 deslocados. INTERNAL DISPLACEMENT MONITORING CENTRE. 2019 Global Report on Internal Displacement (GRID 2019). Genebra, Suíça: IDMC/NRC, 2019. p. 39.

22 INTERNAL DISPLACEMENT MONITORING CENTRE. 2019 Global Report on Internal Displacement (GRID 2019). Genebra, Suíça: IDMC/NRC, 2019. p. 39. bre os processos migratórios decorrentes das mudanças climáticas permanecem essencialmente focadas na urgência de se estabelecer uma terminologia adequada e consensual para descrever o fenômeno. As expressões refugiado ambiental, migrante ambiental e deslocado ambiental vêm sendo comumente utilizadas com o intuito de fazer referência a pessoas ou grupos humanos que, diante da iminência de adversidades ambientais no local de seu habitat tradicional, sejam eles provocados por eventos de ordem natural ou induzidos pela ação humana, compõem a onda migratória tanto no âmbito interno de cada Estado quanto na esfera internacional, de forma voluntária ou forçada, em caráter temporário ou permanente, com vistas ao resguardo das garantias fundamentais da pessoa humana ${ }^{23}$.

O uso de diferentes expressões reflete as divergências existentes entre os grupos de interesses envolvidos e as escolas de pensamento que se debruçam sobre o assunto $^{24}$. Apesar das terminologias propostas terem oportunizado "uma ampla nebulosa de discursos e argumentos políticos que construíram um momentum significativo recentemente" 25 , está-se diante de "vocábulos extremamente controversos" ${ }^{\prime 26}$.

Por essa razão, opta-se pelo uso da locução mobilidade bumana, restringindo-a aos efeitos adversos das mudanças climáticas: "além de ser mais consensual, ela inclui diferentes formas de movimento" 27 , abarcando as nuances das diversas situações inerentes ao tema. Compreendida como "um termo guarda-chuva que se refere a todos os

23 RAMOS, Erika Pires. Refugiados, migrantes ou deslocados ambientais: uma abordagem inspirada na proteção do meio ambiente e nos direitos humanos. In: LEITE, José Rubens Morato (coord.). Manual de direito ambiental. São Paulo: Saraiva, 2015. p. 739.

24 MCADAM, Jane. Climate change, forced migration and international law. Oxford, UK: Oxford University Press, 2012. p. 05

25 MAYER, Benoit. The concept of climate migration: advocacy and its prospects. Cheltenham, UK: Edward Elgar Publishing Limited, 2016. p. 38. Traduzido a partir de: "[...] a broad nebula of political discourses and arguments which have built a significant momentum in recent years, hence, possibly, creating opportunities for reforms in global governance."

26 SAAD, Aaron. Climate change, compelled migration and global social justice. In: SANDBERG, L. Anders; SANDBERG, Tor (ed.). Climate change: Who's carrying the burden? The chilly climates of the global environmental dilemma. Ottawa, Canadá: Our School/Our Selves (OS/OS), 2010. p. 107. Traduzido a partir de: “[...] but the terms are extremely problematic for several reasons."

27 IONESCO, Dina; MOKHNACHEVA, Daria; GEMENE, François. The Atlas of environmental migration. London and New York: Routledge - Taylor and Francis Group, 2017. p. 2. Traduzido a partir de: "Mobility, a more consensual term, includes different forms of movement and refers to the ability to migrate." 
aspectos do movimento de pessoas, a mobilidade humana abrange processos de migração e de deslocamentos (in) voluntários internos e transfronteiriços, assim como a realocação planejada e consentida de populações" 28 .

Nessa esteira, haveria de se falar em três modalidades de fluxos populacionais, aplicadas independentemente da temporalidade e da transposição de fronteiras nacionais: migração, manifestada de forma voluntária; deslocamento, identificado a partir de seu caráter forçado; e realocação planejada, expressa a partir de processos de reassentamentos programados de indivíduos ou grupo de pessoas para uma nova localidade ${ }^{29}$.

Em síntese, enquanto a migração implicaria o total controle sobre a decisão de migrar, o deslocamento seria caracterizado pela falta de opção alternativa à saída do espaço de vida habitual. A migração, portanto, envolve sujeitos que deixam seus locais de residência por motivações pessoais e/ou por entender que os meios garantidores da dignidade da pessoa humana foram, de alguma forma, colocados em risco. $\mathrm{O}$ deslocamento, em contrapartida, refere-se a indivíduos compelidos a abandonar suas moradias, sendo essa a única alternativa viável à manutenção de condições adequadas de sobrevivência. Ambas as modalidades colocam as garantias elementares do ser humano em risco e, à vista disso, é a possibilidade de escolha que acaba por diferenciar uma da outra. É dizer, são as condições do meio ambiente que definem a mobilidade humana como processo migratório ou deslocamento ${ }^{30}$.

Em que pese a relevância da distinção acima, as controvérsias persistem ${ }^{31}$. Isso porque se deve ter em mente

28 ADVISORY GROUP ON HUMAN MOBILITY AND CLIMATE CHANGE. Human mobility in the context of climate change: Elements for the UNFCCC Paris Agreement. Suíça: IOM, 2015. Traduzido a partir de: "[...] an umbrella term that refers to all aspects of the movement of people: human mobility is understood to encompass (in)voluntary internal and cross-border displacement of populations, voluntary internal and cross-border migration and planned and consented relocation."

${ }_{29}$ EXECUTIVE COMMITTEE OF THE WARSAW INTERNATIONAL MECHANISM FOR LOSS AND DAMAGE ASSOCIATED WITH CLIMATE CHANGE IMPACTS. Technical Meeting: Action Area 6 - Migration, Displacement and Human Mobility. Casablanca, Marrocos: IOM, 2016.

30 GEMENE, François. Environmental Migration. In: MARTINIELLO, Marco; RATH, Jan. An introduction to international migration studies: European Perspectives. Amsterdam, Holanda: Amsterdam University Press, 2012. p. 238-257.

31 GEMENE, François. Environmental Migration. In: MARTINIELLO, Marco; RATH, Jan. An introduction to international migration studies: European Perspectives. Amsterdam, Holanda: Amsterdam que os fluxos populacionais costumam ter início de forma espontânea e, com o esgotamento dos recursos que permitem a subsistência e a permanência em uma localidade específica, revertem-se em compulsórios. Logo, a divisão entre migração e deslocamento acaba por se desfazer com frequência, emperrando o estabelecimento de mecanismos que se voltem à regulamentação da questão. Ou seja, "na prática, é difícil distinguir claramente movimentos de caráter forçado e voluntário, o que complica a implementação de respostas políticas apropriadas”32.

Por sua vez, a realocação planejada pressupõe assistência estatal e encontra-se relacionada a pessoas que não poderão ou farão a opção de não retornar aos seus locais de residência habitual. No contexto climático, esse processo está associado a eventos de início lento, como a desertificação e a elevação do nível do mar. O Alto Comissariado das Nações Unidas para os Refugiados (ACNUR) define a expressão nos seguintes termos:

[...] processo planificado no qual pessoas ou grupos de pessoas se mudam ou são auxiliados a deixar suas casas ou locais temporários de residência, sendo acomodados em localidades que lhes permitam o recebimento das condições necessárias para a reconstrução de suas vidas. Além da transferência ser previamente programada sob a autoridade do Estado, ocorrendo dentro das fronteiras nacionais, é realizada com o intuito de proteger seres humanos de riscos e impactos relacionados a desastres e outras mudanças ambientais, incluindo os efeitos adversos das mudanças climáticas ${ }^{33}$.

Trata-se, pois, do movimento permanente - ou de longo prazo - de aglomerados humanos de um local para outro, em que características relevantes, como a estrutura social, sistemas políticos, aspectos culturais e

University Press, 2012. p. 238-257. Traduzido a partir de: “[...] it is also highly controversial, and not as clear-cut as it might seem."

32 IONESCO, Dina; MOKHNACHEVA, Daria; GEMENE, François. The Atlas of environmental migration. London and New York: Routledge - Taylor and Francis Group, 2017. p. 18. Traduzido a partir de: "[...] it is difficult to clearly distinguish between forced and voluntary migration, which complicates the implementation of appropriate political responses."

33 UNITED NATIONS HIGH COMMISSIONER FOR REFUGEES. A Toolbox: planning relocations to protect people from disasters and environmental changes. Suíça: UNHCR e IOM, 2015. p. 3. Traduzido a partir de: "[...] a planned process in which persons or groups of persons move or are assisted to move away from their homes or places of temporary residence, are settled in a new location, and provided with the conditions for rebuilding their lives. Planned Relocation is carried out under the authority of the State, takes place within national borders, and is undertaken to protect people from risks and impacts related to disasters and environmental change, including the effects of climate change." 
visões de mundo, devem ser mantidas: "a comunidade permanece unida no destino final de tal forma que se assemelha à de origem. Considera-se a realocação planejada, sobretudo a de longa distância, uma das formas mais radicais de adaptação às mudanças climáticas"34.

Desse modo, programas de realocação planejada não se restringem à provisão de novas residências e, eventualmente, de estruturas destinadas à prestação de serviços básicos em locais apropriados. Eles também precisam se ocupar da manutenção dos meios de subsistência, bem como de aspectos econômicos e sociais adjacentes: "sua viabilidade deve se basear em fatores sociais e culturalmente adequados, e não apenas na sua exequibilidade econômica" ${ }^{35}$, mantendo o impacto sociocultural intacto.

Pelo exposto, por se tratar de uma temática cujos fundamentos ainda se encontram em fase de desenvolvimento pela agenda internacional contemporânea, torna-se compreensível o por que da inexistência de um regime jurídico próprio, com normas e princípios que reconheçam e tutelem aqueles que são compelidos a abandonar seus locais de origem por conta das mudanças climáticas. Por outro lado, não se pode permitir que a sociedade contemporânea continue ignorando a espinhosa realidade enfrentada por esses indivíduos. Assim, verifica-se, na sequência, a abordagem do tema com base no regime climático internacional.

\subsection{A mobilidade humana sob a perspectiva do regime climático internacional}

Ainda que as pesquisas científicas sobre as alterações induzidas do clima tenham sido iniciadas ao final do século XIX, a emergência das mudanças climáticas como uma questão política ocorreu tão somente ao final da década de 1980. A divulgação de estudos científicos ${ }^{36}$

34 CAMPBELL, John. Climate-induced community relocation in the Pacific: the meaning and importance of land. In: MCADAM, Jane. Climate change and displacement. Multidisciplinary Perspectives. Portland, EUA: Hart Publishing, 2010. p. 59. Traduzido a partir de: "[...] the community stays together at the destination in a social form that is similar to the community of origin. Community relocation, especially over long distances, may be considered as among the most radical forms of adaptation to climate change."

35 KAZMI, Shakeel. Climate change: human rights in the times of climate displacement. Tese (Doutorado) - Elisabeth Haub School of Law, Pace University, White Plains, EUA, 2012. p. 191. Traduzido a partir de: "Their feasibility should be based on socially and culturally appropriate factors rather than their economic viability."

${ }_{36}$ Dentre eles, destaca-se o documento Our Common Future, tam- evidenciando a intensificação da temperatura terrestre levou a comunidade internacional a buscar respostas adequadas por meio da formulação de um regime climático internacional ${ }^{37}$.

O ápice desse processo aconteceu na década de 1990, diante dos debates políticos que conduziram à realização da Conferência das Nações Unidas sobre o Meio Ambiente e Desenvolvimento (CNUMAD), organizada no Brasil em $1992^{38}$. Coube a esse evento "examinar o estado do meio ambiente e as mudanças ocorridas desde 1972, após a Conferência de Estocolmo, [...] levando ainda em conta as atividades desenvolvidas pelos países e organizações intergovernamentais para proteger e melhorar o meio ambiente" ${ }^{\prime 3}$. Da CNUMAD, decorreram três documentos juridicamente vinculantes: a Convenção sobre Diversidade Biologica, a Convenção das Nações Unidas de Combate à Desertificação e Mitigação dos Efeitos da Seca e a Convenção-Quadro das Nações Unidas sobre Mudança do Clima (CQNUMC).

Feita essa breve introdução, são os desdobramentos da CQNUMC que interessam para esta pesquisa. Em vigor desde 1994, com a ratificação de 192 Estados, a Convenção-Quadro é o primeiro acordo formal a reconhecer os efeitos adversos das mudanças climáticas e suas causas antropogênicas. Conforme estabelece o seu artigo $2^{\circ}$, o principal objetivo do documento consiste em "[...] alcançar a estabilização das concentrações de gases de efeito estufa na atmosfera num nível que impeça uma interferência antrópica perigosa no sistema climático" ${ }^{40}$. Sem metas quantificadas, uma regulamentação mais detalhada do acordo acaba sendo postergada para um momento futuro, funcionando esse "como um ponto de partida para a inclusão definitiva do tema no centro das negociações internacionais" ${ }^{\prime 4}$.

bém chamado de Relatório Brundtland, publicado em 1987, assim como o primeiro Relatório de Avaliação do IPCC (AR1), em 1990.

37 BODANSKY, Daniel; BRUNNÉE, Jutta; RAJAMANI, Lavanya. The history of the global climate change regime. In: LUTERBACHER, U.; SPRINZ, D. F. (edit.). International relations and global climate change. Cambridge: MIT Press, 2001. p. 24.

38 RIVERA, M. T. C. El cambio climático: análisis científico y jurídico del problema de la emisión de gases de efecto invernadero. Revista de Derecho Urbanístico y Medio Ambiente, v. 31, n. 156, p. 12091235, 1997.

39 SILVA, Geraldo Eulálio do Nascimento e. Direito Internacional Ambiental. 2 ed. Rio de Janeiro: Thex, 2002. p. 36.

40 ORGANIZAÇÃO DAS NAÇÕES UNIDAS. Convenção-Quadro das Nações Unidas sobre Mudança do Clima. 1992. Disponível em: https://unfccc.int/resource/docs/convkp/conveng.pdf. Acesso em: 15 jun. 2019.

41 MAZZUOLI, Valério de Oliveira. Curso de Direito Internacional 
Atendendo ao Princípio das Responsabilidades Comuns, mas Diferenciada ${ }^{42}$, os países signatários da CQNUMC foram divididos em dois grupos: os países industrializados e responsáveis pela emissão de grandes proporções de dióxido de carbono (CO2) na atmosfera ao longo da história - listados no Anexo I; e os demais países que, para atender às necessidades básicas de desenvolvimento, precisariam aumentar a sua oferta energética e, consequentemente, suas emissões ${ }^{43}$.

Com o intuito de definir, coordenar e implementar medidas consensuais sobre os esforços a serem feitos para combater as mudanças climáticas, uma complexa estrutura de órgãos foi criada. Dentre eles, destaca-se a Conferência das Partes (COP), que é responsável pelo exame periódico do desenvolvimento do acordo e pela tomada das decisões necessárias para promover o seu efetivo funcionamento. Nesse contexto, ressalta-se que são as decisões tomadas nas COPs que "vão formando o tecido normativo internacional para o enfrentamento das causas e efeitos das mudanças climáticas" ${ }^{44}$.

Oportuno individualizar a $3^{a}$ Conferência das Partes (COP3), realizada no Japão em 1997, da qual resultou a aprovação do Protocolo de Quioto ${ }^{45}$. Por meio do referido acordo, determinou-se aos integrantes do Anexo I a redução de suas emissões totais de GEE em, pelo menos, 5\% abaixo dos níveis de 1990 no período compreendido entre 2008 e $2012^{46}$. Para o alcance de

Público. São Paulo: Revista dos Tribunais, 2010. p. 884.

42 Ao reconhecerem que a maior parte das emissões globais históricas e atuais — de GEE advém dos países desenvolvidos, assim como "que as emissões per capita dos países em desenvolvimento ainda são relativamente baixas e que parcela das emissões globais originárias dos países em desenvolvimento crescerá para que eles possam satisfazer suas necessidades sociais e de desenvolvimento", os Estados-membros anuem com a imprescindibilidade de se garantir maior equidade no tratamento das nações em diferentes níveis de progresso industrial. ORGANIZAÇÃO DAS NAÇÕES UNIDAS. Convenção-Quadro das Nações Unidas sobre Mudança do Clima. 1992. Disponível em: https://unfccc.int/resource/docs/convkp/ conveng.pdf. Acesso em: 15 jun. 2019.

43 FERNANDES, Elizabeth Alves. Meio ambiente e direitos humanos: o deslocamento de pessoas por causas ambientais agravadas pelas mudanças climáticas. Curitiba: Juruá, 2014. p. 144.

44 FERNANDES, Elizabeth Alves. Meio ambiente e direitos humanos: o deslocamento de pessoas por causas ambientais agravadas pelas mudanças climáticas. Curitiba: Juruá, 2014. p. 143.

45 LEAL-ARCAS, Rafael. Climate change and international trade. Cheltenham, UK: Edward Elgar Publishing Limited, 2013. p. 190.

46 ORGANIZAÇÃO DAS NAÇÕES UNIDAS. Convenção-Quadro das Naçoes Unidas sobre Mudança do Clima. 1992. Disponível em: https://unfccc.int/resource/docs/convkp/conveng.pdf. Acesso em: 15 jun. 2019. tais metas, três arranjos operacionais, denominados mecanismos de flexibilização ${ }^{47}$, foram disponibilizados. Já os países em desenvolvimento comprometeram-se com a implantação voluntária de sistemas de desenvolvimento sustentável ${ }^{48}$.

O Protocolo de Quioto entrou em vigor apenas em 2005, após a ratificação da Rússia. O primeiro período de compromisso do acordo, entretanto, expirou em 2012, "em contexto de indefinição sobre ações futuras" ${ }^{\prime 49}$. Diante das dificuldades em se estabelecerem novas metas tangíveis de mitigação, designou-se um segundo período de vigência do acordo (2013-2020), a depender da ratificação de três quartos dos signatários do Protocolo, o que ainda não aconteceu. Em verdade, “a decisão da COP18, que ocorreu em 2012, em Doha, prevê a extensão do Protocolo de Quioto até 2020, mas, pela governança climática internacional atual, parece improvável que ações efetivas de mitigação sejam adotadas" ${ }^{\prime \prime}$.

Nesse contexto, a alteração da perspectiva de abordagem do tema fez-se necessária para que as causas das alterações induzidas do clima pudessem ser abordadas adequadamente $^{51}$. Em 2015, chega-se, então, ao Acordo de Paris. Resultado da $21^{\mathrm{a}}$ Conferência das Partes (COP21), o Acordo foi adotado com o propósito de fortalecer o regime climático internacional, tendo como objetivo principal “[...] manter o aumento da temperatura média global bem abaixo de $2^{\circ} \mathrm{C}$ em relação aos níveis pré-industriais, e envidar esforços para limitar esse aumento da temperatura a $1.5^{\circ} \mathrm{C}$ em relação aos níveis pré-industriais" ${ }^{\prime 52}$.

A partir de uma releitura do Princípio das Responsabilidades Comuns, Mas Diferenciadas, o Acordo de Paris requer

47 São eles: o Comércio Internacional de Emissões (CIE), o Mecanismo de Desenvolvimento Limpo (MDL) e a Implementação Conjunta (IC). Ver Artigos 06, 12 e 17 do Protocolo de Quioto.

48 VIÑUALES, Jorge E. El régimen jurídico internacional relativo al cambio climático: perspectivas y prospectivas. Disponível em: http:// www.oas.org/ Acesso em: 15 dez. 2018. p. 269.

49 FERNANDES, Elizabeth Alves. Meio ambiente e direitos humanos: o deslocamento de pessoas por causas ambientais agravadas pelas mudanças climáticas. Curitiba: Juruá, 2014. p. 145.

50 FERNANDES, Elizabeth Alves. Meio ambiente e direitos humanos: o deslocamento de pessoas por causas ambientais agravadas pelas mudanças climáticas. Curitiba: Juruá, 2014. p. 147.

51 BODANSKY, Daniel; BRUNNÉE, Jutta; RAJAMANI, Lavanya. International climate change law. Oxford, UK: Oxford University Press, 2017. p. 12.

52 UNITED NATIONS. Convenção-Quadro das Nações Unidas sobre Mudança Climática. 2015. Disponível em: http://www.br.undp.org/ content/dam/brazil/docs/ODS/.... Acesso em: 15 jun. 2019. 
o envolvimento de todos os governos nacionais na edificação de seus próprios compromissos a partir das chamadas Contribuicõoes Nacionalmente Determinadas (NDCs) ${ }^{53}$. Por meio das NDCs, cada nação apresenta suas colaborações no que diz respeito à redução de emissões de GEE, "seguindo o que cada governo considera viável a partir do cenário social e econômico local" ${ }^{54}$.

Assim, enquanto o Protocolo de Quioto enunciava obrigações de resultado, impondo metas específicas que poderiam ser alcançadas por meio de um dos mecanismos de flexibilização, o Acordo de Paris desenvolveu-se a partir de obrigações de conduta, não estabelecendo objetivos de mitigação particulares a serem cumpridos pelos Estados-membros ${ }^{55}$. Como cabe a cada um quantificar a redução das emissões de GEE que está ao seu alcance por meio das NDCs, permitindo um maior engajamento e participação efetiva das Partes: "muito embora estejam atreladas a uma perspectiva progressiva de metas, as NDCs são, em última análise, autodeterminadas, possibilitando a participação dos países independentemente das diferentes circunstâncias nacionais" ${ }^{\prime 56}$.

Traçado esse breve panorama sobre o regime climático internacional, retoma-se a CQNUMC, que nada menciona sobre a proteção de pessoas cuja subsistência resta ameaçada em razão das mudanças climáticas. Verdade seja, "a Convenção do Clima não foi estruturada para lidar com a questão migratória das populações afetadas, nem no âmbito interno dos países, nem daqueles casos mais graves em que os migrantes cruzam as fronteiras de seu país de origem" 57 .

A mobilidade humana no contexto das alterações induzidas do clima só foi abordada expressamente no

\footnotetext{
53 BRASIL. Ministério do Meio Ambiente. Acordo de Paris. Disponível em: https://www.mma.gov.br/clima/convencao-das-nacoes-unidas/acordo-de-paris Acesso em: 15 dez. 2018.

54 BRASIL. Ministério do Meio Ambiente. Acordo de Paris. Disponível em: https://www.mma.gov.br/clima/convencao-das-nacoes-unidas/acordo-de-paris Acesso em: 15 dez. 2018.

55 BODANSKY, Daniel; BRUNNÉE, Jutta; RAJAMANI, Lavanya. International climate change law. Oxford, UK: Oxford University Press, 2017. p. 24-25.

56 BODANSKY, Daniel; BRUNNÉE, Jutta; RAJAMANI, Lavanya. International climate change law. Oxford, UK: Oxford University Press, 2017. p. 25. Traduzido a partir de: "[...] although these are subject to expectations of 'progression' [...] they are ultimately self-determined, making it possible for countries across the entire spectrum of differing national circumstances to participate."

57 MATTOS, Ana Carolina Barbosa Pereira; MONT'ALVERNE, Tarim Cristino Frota. O regime internacional do clima e a proteção aos "refugiados climáticos": quais desafios da COP21? Revista de Direito Internacional, Brasília, v. 13, n. 2, 2016. p. 60.
}

regime climático internacional em 2010, durante a $16^{a}$ Conferência das Partes (COP16), realizada em Cancun. Em suma, a COP16 permitiu a inclusão definitiva da adaptação na pauta das negociações climáticas. A instituição do Marco de Adaptação de Cancun, criado para fomentar ações adaptativas nos países em desenvolvimento por meio da cooperação internacional, tornou possível a elaboração e a implementação dos chamados Planos Nacionais de Adaptação (PNAs), os quais almejam "a redução das vulnerabilidades aos impactos das mudanças do clima por meio do fortalecimento de capacidades adaptativas e resiliência, facilitando a integração, de forma coerente, da adaptação a políticas e processos de desenvolvimento" 58 .

É no contexto do planejamento de estratégias de adaptação, portanto, que a mobilidade humana passa a integrar essa esfera da governança global. Nesse sentido, o parágrafo 14(f) do relatório final da COP16 prevê a necessidade de se reforçarem as ações em matéria de adaptação, compreensão, coordenação e cooperação no que tange a processos migratórios, deslocamentos e realocações planejadas induzidos pelas alterações climáticas nos níveis nacional, regional e internacional ${ }^{59}$. No entanto, ainda que tenha havido o reconhecimento das Partes em relação à importância da adoção de medidas para lidar com as questões ligadas aos deslocamentos induzidos pelo câmbio climático, nenhum compromisso de caráter cogente foi assumido com essa finalidade" ${ }^{90}$.

Dois anos mais tarde, durante a $18^{\mathrm{a}}$ Conferência das Partes (COP18), propôs-se a facilitação de medidas compensatórias aos prejuízos ocasionados pelos efeitos adversos das mudanças climáticas, sobretudo para as nações mais vulneráveis do globo, por meio de um instrumento jurídico de perdas e danos, adotado na COP subsequente. Por meio da Decisão 3/CP.18, reconheceu-se, expressamente, "a necessidade de melhorar a compreensão da maneira pela qual os impactos

\footnotetext{
58 CARVALHO, Fernanda Viana de. Assuntos estratégicos: adaptação à mudança do clima: o quadro das negociações internacionais. Brasília: Secretaria de Assuntos Estratégicos da Presidência da República, 2014. p. 15.

59 UNITED NATIONS. Report of the Conference of the Parties on its sixteenth Session, beld in Cancun from 29 November to 10 December 2010. Disponível em: http://unfccc.int/resource/docs/2010/ cop16/ eng/07a01.pdf. Acesso em: 10 jan. 2019.

${ }_{60}$ BURKETT, Maxine. Justice and climate migration: the importance of nomenclature in the discourse on twenty-first-century mobility. In: BEHRMAN, Simon; KENT, Avidan. Climate Refugees: beyond the legal impasse? EUA: Routledge Studies in Environmental Migration, Displacement and Resettlement, 2018. p. 198.
} 
das mudanças climáticas estão afetando a migração, o deslocamento e a mobilidade humana" ${ }^{61}$.

Como resultado, a $19^{\text {a }}$ Conferência das Partes (COP19), realizada em 2013, instituiu o Mecanismo Internacional de Varsóvia sobre Perdas e Danos (WIM), "com o objetivo de prestar assistência técnica e financeira e apoio aos países mais pobres que são desproporcionalmente afetados pelas mudanças climáticas" ${ }^{\prime 2}$. Frisa-se que,

[...] politicamente, o Mecanismo de Varsóvia pode ser considerado uma vitória relevante, dado que fez prevalecer a visão dos países em desenvolvimento a respeito do tema (como algo distinto da agenda de adaptação, merecendo tratamento específico), enquanto os países desenvolvidos prefeririam tratar o tema como parte dos tradicionais trilhos de mitigação e adaptação ${ }^{63}$.

O WIM conta com um Comitê Executivo, "com representação equilibrada entre países desenvolvidos e em desenvolvimento" "64. Esse Comitê inseriu a mobilidade humana induzida pelo clima entre os temas a serem analisados no seu plano de trabalho inicial de dois anos. A Área de Ação n. 06 do plano visa promover uma melhor compreensão, assim como produzir conhecimentos "sobre como os impactos das mudanças climáticas estão afetando os padrões de migração, deslocamento e mobilidade humana" ${ }^{\prime 65}$.

No tocante a essa temática, o Comitê Executivo preliminarmente buscou aprimorar o conhecimento que se tem a respeito das relações existentes entre mobilidade

${ }_{61}$ UNITED NATIONS. Report of the Conference of the Parties on its Eighteenth Session, held in Doha from 26 November to 8 December 2012. 2013. Disponível em: http://unfccc. int/resource/docs/2012/ cop18/eng/08a01.pdf. Acesso em: 10 jan. 2019. Traduzido a partir de: "7. Acknowledges the further work to advance the understanding of and expertise on loss and damage, which includes, inter alia, the following: [...] (a) Enhancing the understanding of: [...] (vi) How impacts of climate change are affecting patterns of migration, displacement and human mobility; [...]." In:

62 MATTOS, Ana Carolina Barbosa Pereira; MONT'ALVERNE, Tarim Cristino Frota. O regime internacional do clima e a proteção aos "refugiados climáticos": quais desafios da COP21? Revista de Direito Internacional, Brasília, v. 13, n. 2, 2016. p. 62.

63 CARVALHO, Fernanda Viana de. Assuntos estratégicos: adaptação à mudança do clima: o quadro das negociações internacionais. Brasília: Secretaria de Assuntos Estratégicos da Presidência da República, 2014. p. 12.

64 CARVALHO, Fernanda Viana de. Assuntos estratégicos: adaptação à mudança do clima: o quadro das negociações internacionais. Brasília: Secretaria de Assuntos Estratégicos da Presidência da República, 2014. p. 12.

65 UNITED NATIONS. Report of the Conference of the Parties on its Nineteenth Session. 2014. Disponível em: http://unfccc.int/resource/ docs/2013/cop19/eng/10a01.pdf. Acesso em: 15 jun. 2019. humana e mudanças climáticas a partir de dados científicos consistentes, abarcando as peculiaridades das comunidades vulneráveis que podem vir a abandonar seus habitats em razão do aquecimento global. Semelhantemente, sintetizou "as informações coletadas relevantes, as lições aprendidas e as boas práticas das atividades desempenhadas por organizações e especialistas" $"$.

Os resultados desse processo foram vistos no Acordo de Paris, que, enfim, previu "uma medida concreta para o desenvolvimento da mobilidade humana no

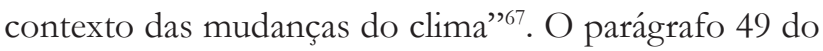
texto acordado fez constar um pedido direcionado ao Comitê Executivo do WIM no sentido de que fossem estabelecidas "recomendações para abordagens integradas visando prevenir, minimizar e tratar dos deslocamentos relacionados aos impactos adversos das alterações climáticas ${ }^{\prime 68}$. Para tanto, deveria ser estabelecida uma força-tarefa com o envolvimento de órgãos e grupos de especialistas vinculados à Convenção-Quadro ou externos a ela.

Ainda que a menção ao tema por meio do "estabelecimento de uma força-tarefa tenha sido vaga, essa oportunizou um novo leque de oportunidades" ${ }^{69}$. De acordo com Behrman e Kent ${ }^{70}$, enfrentar os desafios inerentes

${ }_{66}$ MATTOS, Ana Carolina Barbosa Pereira; MONT'ALVERNE, Tarim Cristino Frota. O regime internacional do clima e a proteção aos "refugiados climáticos": quais desafios da COP21? Revista de Direito Internacional, Brasília, v. 13, n. 2, 2016. p. 63.

67 CAPDEVILLE, Fernanda de Salles Cavedon. A mobilidade humana na agenda global do clima: uma questão de justiça climática. In: LEITE, José Rubens Morato; DINNEBIER, Flávia França (org.). Estado de Direito Ecológico: Conceito, conteúdo e novas dimensões para a proteção da natureza. São Paulo: Instituto O Direito por um Planeta Verde, 2017. p. 493.

68 UNITED NATIONS. Report of the Conference of the Parties on its twenty-first Session: held in Paris from 30 November to 13 December 2015. Disponível em: http://unfccc.int/resource/docs/2015/cop21/ eng/10a01.pdf. Acesso em: 10 jun. 2019. Traduzido a partir de: Conforme o item 49 da Decisão 1/CP. 21: "[...] to develop recommendations for integrated approaches to avert, minimize and address displacement related to the adverse impacts of climate change; [...]."

69 JAKOBSSON, Elin. Norm formalization in International Policy Cooperation. In: BEHRMAN, Simon; KENT, Avidan. Climate Refugees: beyond the Legal impasse? EUA: Routledge Studies in Environmental Migration, Displacement and Resettlement, 2018. p. 65. Traduzido a partir de: "The mention of displacement in the outcomes from Paris and the establishment of a task-force is vague, but it comes with a number of different possibilities."

70 BEHRMAN, Simon; KENT, Avidan. Overcoming the legal impasse? Setting the scene. In: BEHRMAN, Simon; KENT, Avidan. Climate Refugees: beyond the legal impasse? EUA: Routledge Studies in Environmental Migration, Displacement and Resettlement, 2018. p. 9. Traduzido a partir de: "In our view addressing the challenge of climate refugees via the international environmental regime is indeed the most attractive 
à mobilidade humana no contexto dos efeitos adversos das mudanças climáticas "a partir do regime ambiental - climático - internacional designa-se, de fato, como o caminho mais promissor" para a adoção de medidas concretas, visto que "os princípios dessa esfera de governança mostram-se como os mais adequados para a formulação de uma estrutura jurídica futura".

Trata-se, pois, de "uma indicação de que, finalmente, a CQNUMC passou a assumir algum tipo de responsabilidade pela infeliz situação dos chamados refugiados climáticos. Ademais, a aprovação da força-tarefa sugere que a CQNMUC seja tida como líder desse processo pela comunidade internacional, sem afastar o apoio de outras organizações" ${ }^{\prime 11}$.

Assim, desde então, a força-tarefa do Comitê Executivo do WIM passou a ser a arena de discussões a lidar com o tema na agenda global do clima. Tendo em vista o prazo de dois anos para a apresentação dos resultados, a implementação e o início das atividades da Força-Tarefa sobre Deslocamento (TFD) foram organizados a partir de três eixos principais: o aprimoramento do conhecimento e da compreensão da mobilidade humana em razão das mudanças climáticas; o fortalecimento do diálogo, da coordenação, da coerência e da sinergia entre os diferentes atores; e o estabelecimento de ações futuras para o devido manejo das perdas e danos associados às alterações induzidas do clima ${ }^{72}$.

Os resultados obtidos pela TFD foram publicados na $24^{a}$ Conferência das Partes (COP24), realizada em Katowice, no fim de $2018^{73}$. O relatório apresentado reconhece que os impactos das alterações induzidas do clima repercutem entre os fatores que levam a proces-

future pathway. The principles of this regime are the most suitable for the design of a future framework."

${ }_{71}$ BEHRMAN, Simon; KENT, Avidan. Overcoming the legal impasse? Setting the scene. In: BEHRMAN, Simon; KENT, Avidan. Climate Refugees: beyond the legal impasse? EUA: Routledge Studies in Environmental Migration, Displacement and Resettlement, 2018. p. 9. Traduzido a partir de: "[... an indication that at long last, the UNFCCC is taking some sort of responsibility for the unfortunate situation of climate-refugees. Also the 'membership' of this task force suggests that the international community is viewing the UNFCCC as the 'leader' of such process, and with other organizations fulfilling more supportive and complementary roles."

${ }^{72}$ UNITED NATIONS. Task Force on Displacement at a glance. 2017. Disponível em: https://unfccc.int/sites/default/files/resource/ TFD_brochure.pdf. Acesso em: 10 jun. 2019.

73 UNITED NATIONS. Report of the Task Force on Displacement. 2018. Disponível em: https://unfccc.int/sites/default/files/resource/2018_TFD_report_17_Sep.pdf. Acesso em: 10 jan. 2018. sos migratórios, deslocamentos e realocações planejadas, destacando a necessidade de "se aprimorar as pesquisas sobre a influência das mudanças climáticas sobre outros fatores de deslocamento (incluindo conflitos), bem como suas interconexões" ${ }^{\prime 74}$. A TFD aponta, ademais, que a carência de informações concretas e metodologias robustas atrapalham governos nacionais e outras organizações no monitoramento, na medição e no gerenciamento de fluxos populacionais que decorrem do aquecimento do sistema climático terrestre ${ }^{75}$. Por fim, recomenda o uso do termo mobilidade humana para designar as diferentes modalidades de movimentos no contexto dos efeitos adversos das mudanças climáticas - migração, deslocamento e realocação planejada englobando o maior número possível de pessoas nas medidas protetivas a serem desenvolvidas ${ }^{76}$.

A delegação estruturada para a força-tarefa incumbiu-se, ainda, da análise de como a mobilidade humana no contexto das mudanças climáticas tem sido integrada a processos políticos em andamento no âmbito internacional. Após o mapeamento de estruturas jurídicas relevantes, concluiu-se que a inclusão da mobilidade humana e as preocupações com as alterações induzidas do clima cresceram de forma considerável a partir de 2015, diante da homologação do Acordo de Paris ${ }^{77}$. Ainda segundo o relatório apresentado pela TFD, trata-se de uma tendência visível nas mais variadas esferas de governança, e particularmente significativa nas agendas que abordam mobilidade humana, de um lado, e as alterações climáticas e o meio ambiente, de outro ${ }^{78}$.

74 UNITED NATIONS. Report of the Task Force on Displacement. 2018. Disponível em: https://unfccc.int/sites/default/files/resource/2018_TFD_report_17_Sep.pdf. Acesso em: 10 jan. 2018. p. 17. Traduzido a partir de: "Improve research on impacts of slow onset on other drivers of displacement (including conflicts) and inter-relationship of these drivers [...7."

75 UNITED NATIONS. Report of the Task Force on Displacement. 2018. Disponível em: https://unfccc.int/sites/default/files/resource/2018_TFD_report_17_Sep.pdf. Acesso em: 10 jan. 2018. p. 09.

76 UNITED NATIONS. Report of the Task Force on Displacement. 2018. Disponível em: https://unfccc.int/sites/default/files/resource/2018_TFD_report_17_Sep.pdf. Acesso em: 10 jan. 2018. p. 09.

77 UNITED NATIONS. Report of the Task Force on Displacement. 2018. Disponível em: https://unfccc.int/sites/default/files/resource/2018_TFD_report_17_Sep.pdf. Acesso em: 10 jan. 2018. p. 23.

78 UNITED NATIONS. Report of the Task Force on Displacement. 2018. Disponível em: https://unfccc.int/sites/default/files/resource/2018_TFD_report_17_Sep.pdf. Acesso em: 10 jan. 2018. p. 23. 
Contudo, as recomendações ora mencionadas apenas sugerem que os embates que permeiam o assunto continuarão sendo discutidos, sem garantias de que medidas concretas serão adotadas em um futuro próximo. Levando-se em consideração experiências do passado, frisa-se que "a CQNUMC nunca foi de entregar resultados rápidos e significativos. Assim sendo, ao que tudo indica, a jornada poderá ser longa, tortuosa e, possivelmente, infrutífera" 79 .

Indaga-se, desde logo, se a força-tarefa foi realmente criada como um primeiro passo para a instituição de respostas adequadas ou tão somente como uma estratégia política para postergar a adoção de ações indispensáveis. Quando se está diante da formulação de novas diretrizes internacionais, "sugestiona-se que tomadores de decisão abordam questões sensíveis a partir de respostas que lhes permitam mostrar que estão fazendo algo relacionado ao assunto, sendo essas fracas o bastante para afastá-los de quaisquer obrigações vinculantes" ${ }^{\prime 80}$.

Ao prorrogar o prazo da TFD por cinco anos para continuar aprimorando a compreensão acerca do fenômeno, o WIM pode desempenhar papel fundamental para a futura implementação de medidas efetivas. Em verdade, como os trabalhos "da força-tarefa encontram-se em estágio de desenvolvimento, torna-se difícil avaliar seu direcionamento no futuro" $"$.

Em que pese o trabalho realizado pela TFD nos seus dois anos iniciais tenha sido primordial para a consagração do tópico em âmbito internacional, "a tarefa a seguir permanece sendo desafiadora, uma vez que nações costumam ser representadas por diferentes en-

BEHRMAN, Simon; KENT, Avidan. Overcoming the legal impasse? Setting the scene. In: BEHRMAN, Simon; KENT, Avidan. Climate Refugees: beyond the legal impasse? EUA: Routledge Studies in Environmental Migration, Displacement and Resettlement, 2018. p. 9. Traduzido a partir de: "The developments described above provides so far only a promise in this respect, and based on past experience the UNFCCC was never one to deliver quick and meaningful results. The journey, so it seems, is expected to be long and bumpy, and possibly fruitless."

80 JAKOBSSON, Elin. Norm formalization in International Policy Cooperation. In: BEHRMAN, Simon; KENT, Avidan. Climate Refugees: beyond the Legal impasse? EUA: Routledge Studies in Environmental Migration, Displacement and Resettlement, 2018. p. 66. Traduzido a partir de: "[...] has suggested that a strategy for policy makers to address sensitive issues is to create a response that allows them to show that they are doing something about the issue, but that, at the same time, is weake enough to relive them of any binding promises."

81 IONESCO, Dina; MOKHNACHEVA, Daria; GEMENE, François. The Atlas of environmental migration. London and New York: Routledge - Taylor and Francis Group, 2017. p. 109. tidades nas negociações climáticas globais" ${ }^{2}$. Faz-se necessário, diante disso, a coordenação não somente a nível global, mas também nas esferas regionais e nacionais. Diante disso, torna-se oportuno examinar como os avanços constatados pela TFD a partir do regime climático internacional vêm sendo integrados pelos países que compõem a América Latina e o Caribe, estimulando o reconhecimento da urgência de medidas a fim de se conferir um tratamento adequado para o tema.

\section{A integração da mobilidade humana na agenda climática dos países latino-americanos e caribenhos}

De acordo com o AR5 do IPCC, a América Latina ${ }^{83}$ e o Caribe ${ }^{84}$ estão dentre as áreas mais suscetíveis às mudanças climáticas em âmbito internacional, visto que a maior incidência de eventos extremos na região tem sido acompanhada de perdas humanas e econômicas significativas. A variabilidade dos padrões climáticos, somada às desigualdades socioeconômicas, à falta de capacidade adaptativa, bem como ao alto grau de vulnerabilidade, expõem comunidades inteiras aos seus efeitos adversos, obrigando-as, às vezes, a abandonar seus locais de residência habitual ${ }^{85}$.

À vista disso, e diante da ausência de instrumentos jurídicos capazes de proteger indivíduos que estão sujeitos à mobilidade humana no contexto das alterações induzidas do clima, examina-se a seguir como as reco-

82 IONESCO, Dina; MOKHNACHEVA, Daria; GEMENE, François. The Atlas of environmental migration. London and New York: Routledge - Taylor and Francis Group, 2017. p. 109.

83 Nela habitam cerca de 570 milhões de pessoas espalhadas em 21 países: Argentina, Belize, Bolívia, Brasil, Chile, Colômbia, Costa Rica, El Salvador, Equador, Guatemala, Guiana Francesa, Guiana, Honduras, México, Nicarágua, Panamá, Paraguai, Peru, Suriname, Uruguai e Venezuela.

84 A faixa de mar aberto - por vezes caracterizada como uma subregião da América Latina - é constituída por 13 nações, quais sejam: Antígua e Barbuda, Bahamas, Barbados, Cuba, Dominica, Granada, Haiti, Jamaica, República Dominicana, Santa Lucia, São Cristóvão e Nevis, São Vicente e Granadinas, e Trinidade e Tobago; sem mencionar os inúmeros departamentos ultramarinos pertencentes aos Estados Unidos da América (EUA), França e Reino Unido.

85 INTERGOVERNMENTAL PANEL ON CLIMATE CHANGE. Working Group I Contribution To The IPCC Fifth Assessment Report. Climate Change 2013: the Physical Science Basis. Sweden: 2013. 
mendações oriundas do regime climático internacional contemporâneo vêm sendo integradas pelos 34 países que compõem a América Latina e o Caribe. Para tanto, além dos Planos Nacionais de Adaptação (PNAs) e das Contribuições Nacionalmente Determinadas (NDCs) submetidas à CQNUMC, as legislações nacionais de cunho climático de cada um desses países também foram analisadas.

\subsection{A incorporação do tópico a partir dos Planos Nacionais de Adaptação (PNAS)}

Não obstante as evidências indicando que os impactos associados às alterações induzidas do clima influenciam a vida na superfície terrestre, a inclusão efetiva da adaptação na pauta das negociações climáticas só ocorreu em 2010, durante a COP16, por meio da instituição do Marco de Adaptação de Cancun, documento que recomenda aos países em desenvolvimento a elaboração e a implementação dos chamados Planos Nacionais de Adaptação (PNAs), conforme mencionado previamente ${ }^{86}$.

Até o momento, dos 37 países que apresentaram seus PNAs ou estratégias similares de adaptação aos efeitos adversos das mudanças climáticas, apenas quatro pertencem aos países que compõem a América Latina e o Caribe. São eles: Brasil, Chile, Colômbia e Santa Lúcia.

De início, o PNA do Brasil, disponibilizado em maio de 2016, menciona que "os impactos das mudanças do clima já são observados na atualidade", reconhecendo a incidência de eventos climáticos extremos cada vez mais frequentes e, consequentemente, "deslocamentos populacionais das regiões atingidas". No mesmo sentido, dentre os "possíveis impactos — desse fenômeno para o Brasil e a América Latina", o documento elenca "o deslocamento e migração de populações"

O plano anseia a promoção "da gestão e redução do risco climático no país frente aos efeitos adversos das mudanças climáticas, de forma a aproveitar as oportunidades emergentes, evitar perdas e danos e construir instrumentos que permitam a adaptação dos sistemas

\footnotetext{
CARVALHO, Fernanda Viana de. Assuntos estratégicos: adaptação à mudança do clima: o quadro das negociações internacionais. Brasília: Secretaria de Assuntos Estratégicos da Presidência da República, 2014. p. 15.

87 BRASIL. Ministério do Meio Ambiente. Plano Nacional de Adaptação à Mudança do Clima: Volume 1 - Estratégia Geral. 2016. Disponível em: http://www.pbmc.coppe.ufrj.br/documentos/PNAVolume1.pdf Acesso em: 20 jun. 2019.
}

naturais, humanos, produtivos e de infraestrutura" Para tanto, visa assegurar a implementação de medidas de adaptação que devem ser desenvolvidas a partir de estratégias setoriais e temáticas de gestão de risco pelo período de quatro anos (2016-2020). Dentre essas, destaca-se a Estratégia de Povos e Populações Vulneráveis, categórica ao afirmar que:

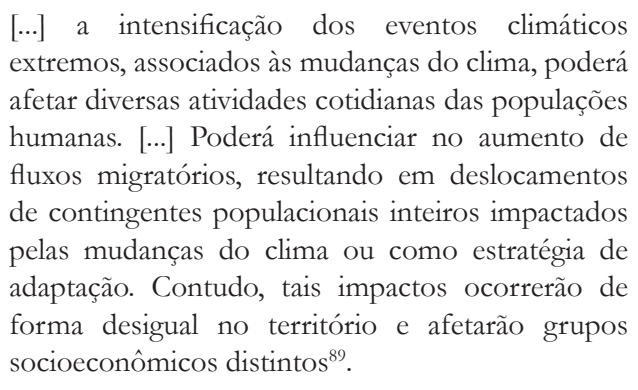

Além de fazer menção expressa ao conceito de migrante ambiental estabelecido pela Organização Internacional para as Migrações (OIM) em 20070, o documento sublinha que "migração e mobilidade são estratégias de adaptação em todas as regiões do mundo que experimentam a variabilidade climática" ${ }^{91}$. Ou seja, quando relacionada a infortúnios ambientais, sustenta-se que a migração deve ser adotada como recurso viável diante do esgotamento de todas as outras opções possíveis de adaptação no local de origem, funcionando como uma ferramenta programada para refrear eventuais prejuízos no futuro.

Por sua vez, o PNA do Chile, publicado em se-

88 BRASIL. Ministério do Meio Ambiente. Plano Nacional de Adaptação à Mudança do Clima: Volume 2 - Estratégia Setoriais e temáticas. 2016. p. 18. Disponível em: https://www.mma.gov.br/images/ arquivo/80182/LIVRO_PNA_Plano\%20Nacional_V2.pdf Acesso em: 20 jun. 2019.

89 BRASIL. Ministério do Meio Ambiente. Plano Nacional de Adaptação à Mudança do Clima: Volume 2 - Estratégia Setoriais e temáticas. 2016. p. 18. Disponível em: https://www.mma.gov.br/images/ arquivo/80182/LIVRO_PNA_Plano\%20Nacional_V2.pdf Acesso em: 20 jun. 2019. Disponível em: [http://www.mma.gov.br/]. Acesso em: 20 jun. 2019.

90 A OIM define migrantes ambientais como "[...] pessoas ou grupo de pessoas que, em razão de mudanças imperiosas ou súbitas no ambiente, as quais afetam negativamente suas vidas ou condições de vida, obrigam-se a deixar suas residências habituais, ou optam por fazê-lo, temporária ou permanentemente, e que se movem tanto no seu país ou no estrangeiro". ORGANIZAÇÃO INTERNACIONAL PARA AS MIGRAÇÕES. Migration, environment and climate change: Assessing the evidence. Suíça: IOM, 2009. p. 19.

91 BRASIL. Ministério do Meio Ambiente. Plano Nacional de Adaptação à Mudança do Clima: Volume 2 - Estratégia Setoriais e temáticas. 2016. p. 143. Disponível em: https://www.mma.gov.br/images/ arquivo/80182/LIVRO_PNA_Plano\%20Nacional_V2.pdf Acesso em: 20 jun. 2019. 
tembro de 2017, centra-se na adoção de medidas que priorizem indivíduos, comunidades e infraestruturas vulneráveis às alterações induzidas do clima, servindo de "complemento e apoio a outras políticas ambientais e/ou setoriais que maximizem benefícios mútuos, tais como: a gestão da redução de risco desastres, a redução de emissões de GEE, a redução da poluição atmosférica local, dentre outros" $"$.

No que tange à mobilidade humana no contexto das mudanças climáticas, ao mencionar os possíveis efeitos adversos desse fenômeno no território chileno, o plano tão somente reconhece que a maior frequência e intensidade de eventos climáticos extremos pode "impactar negativamente" os "padrões populacionais, a urbanização e as condições socioeconômicas", sem abordar o tópico em seus planos setoriais ${ }^{93}$. A implementação de medidas adaptativas a serem adotadas pelo país deve, desse modo, primar pela redução do grau de vulnerabilidade a que diversas comunidades encontram-se expostas $^{94}$.

Semelhantemente, o PNA da Colômbia, submetido à CQNUMC em fevereiro de 2018, enfatiza que os impactos das alterações induzidas do clima afetam, sobretudo, as camadas mais pobres da sociedade. Como essas costumam habitar áreas de riscos, como locais suscetíveis a inundações e/ou deslizamentos, a ocorrência de fenômenos climáticos extremos "pode gerar situações de deslocamento e migração" 95 .

Apesar de citar duas das modalidades da mobilidade bumana como possíveis consequências de eventos climáticos extremos, o plano colombiano não oferece medidas específicas para solucionar questões relacionadas

92 CHILE. Ministerio del Medio Ambiente. Plan Nacional de Adaptación al Cambio Climático. 2017. p. 8. Disponível em: https://www4. unfccc.int/sites/.... Acesso em: 10 jun. 2019. Traduzido a partir de: "[...] complemento y soporte de otras politicas ambientales y/ o sectoriales, que maximicen los beneficios mutuos tales como: la gestión de desastres, la reducción de las emisiones de gases efecto invernadero, la reducción de la contaminación atmosférica local, las politicas de fomento al riesgo, entre otros".

93 CHILE. Ministerio del Medio Ambiente. Plan Nacional de Adaptación al Cambio Climático. 2017. p. 14. Disponível em: https://www4. unfccc.int/sites/.... Acesso em: 10 jun. 2019. Traduzido a partir de: "[...] impactar negativamente [...]" e "[...] los patrones de la población, la urbanización y los cambios en las condiciones socioeconómicas [...]".

94 CHILE. Ministerio del Medio Ambiente. Plan Nacional de Adaptación al Cambio Climático. 2017. p. 52. Disponível em: https://www4. unfccc.int/sites/.... Acesso em: 10 jun. 2019

95 CHILE. Ministerio del Medio Ambiente. Plan Nacional de Adaptación al Cambio Climático. 2017. p. 38. Disponível em: https://www4. unfccc.int/sites/.... Acesso em: 10 jun. 2019. Traduzido a partir de: "[...] Estos eventos pueden generar situaciones de desplazamiento y migración." ao tema. A estratégia frisa, contudo, que o levantamento do número de pessoas deslocadas, seja em caráter temporário ou permanente, pode ser utilizado para a quantificação dos impactos socioeconômicos relacionados às mudanças climáticas, favorecendo, assim, a adoção de ações adaptativas apropriadas ${ }^{96}$.

Por fim, tem-se o PNA de Santa Lúcia, apresentado em setembro de 2018. Trata-se de um plano de ação de dez anos (2018-2028) que visa ao aprimoramento da capacidade adaptativa em âmbito nacional a partir do desenvolvimento de 08 planos setoriais específicos ${ }^{97}$. Em verdade, a ocorrência de eventos extremos tem acentuado a vulnerabilidade do país aos riscos climáticos, suscitando discussões acerca das perdas que os efeitos adversos das alterações induzidas do clima podem vir a ocasionar na ilha ${ }^{98}$.

Além de revelar que "o custo da inércia à rápida mudança climática em Santa Lúcia foi calculado em 12.1\% do PIB até o ano de 2025 , subindo para $24.5 \%$ até 2050 e $49.1 \%$ até 2100 "99, o PNA do país insular sublinha, ainda, que

[...] as despesas ocasionadas pelos impactos do furacão Tomas (2010) corresponderam o montante de $43.4 \%$ do PIB da ilha naquele ano. [...] De igual modo, em 2013, um sistema de baixa pressão atravessou o território e resultou em mais de 224 milímetros ( $\mathrm{mm}$ ) de chuva em um período de duas a três horas. O evento afetou diretamente 2.600 pessoas, levou 06 indivíduos a óbito, destruiu 47

96 Nesse contexto: "[...] se identifican y caracterizan los elementos que integran el sistema sobre el cual se va a planear una estrategia de adaptación al cambio climático, con miras a generar métricas para cuantificar los impactos que se pueden presentar en caso de que se materialicen los eventos amenazantes". COLOMBIA. Departamento Nacional de Planeación. Plan Nacional de Adaptación al Cambio Climático. 2018. p. 90. Disponível em: https:/ / www4.unfccc.int/sites/NAPC/Documents/Parties/Colombia... Acesso em: 20 jun. 2019.

97 Os 08 planos setoriais específicos abordam, respectivamente, medidas de adaptação relacionadas à recursos hídricos, à agricultura, à pesca, à infraestrutura e planejamento urbano, ao gerenciamento de recursos naturais, à educação, à saúde e ao turismo.

98 SANTA LUCIA. Department of Sustainable Development, Ministry of Education, Innovation, Gender Relations and Sustainable Development. Saint Lucia's National Adaption Plan: 2018-2028. 2018. Disponível em: https://www4.unfccc.int/sites/NAPC/Documents/Parties/SLU-NAP-May-2018.pdf. Acesso em: 20 jun. 2019. 99 SANTA LUCIA. Department of Sustainable Development, Ministry of Education, Innovation, Gender Relations and Sustainable Development. Saint Lucia's National Adaption Plan: 2018-2028. 2018. p. 18. Disponível em: https://www4.unfccc.int/sites/NAPC/ Documents/Parties/SLU-NAP-May-2018.pdf. Acesso em: 20 jun. 2019. Traduzido a partir de: "The cost of inaction on climate change in Saint Lucia has been calculated to be at 12.1\% of GDP by 2025, rising to $24.5 \%$ by 2050 and $49.1 \%$ by $2100 . "$ 
residências e provocou prejuízos na monta de US\$ 89.2 milhões $^{100}$.

Além da intensificação dos eventos de início súbito, o plano apresentado por Santa Lúcia indica que a elevação do nível do mar também está entre as consequências das mudanças climáticas, o que levará a processos migratórios por conta de sucessivas inundações e gradativa erosão da zona costeira. Por se tratar de um Pequeno Estado Insular em Desenvolvimento (PEID), essas consequências propiciarão "a realocação de infraestruturas e comunidades em situação crítica, assim como custos e problemas adicionais associados à limitação de áreas adequadas. Isso ensejará o aumento das despesas com a realocação, a substituição e/ou a reparação da infraestrutura danificada ou deslocada" ${ }^{\text {101 }}$.

Ao estabelecer seu plano de adequação às alterações induzidas do clima, o governo de Santa Lúcia inovou, ao consignar os chamados limites à adaptação, reconhecendo que tais processos nem sempre evitarão que os efeitos adversos das mudanças climáticas aconteçam ${ }^{102}$. À vista disso, o PNA refere-se à necessidade de implementação de mecanismos de perdas e danos ${ }^{103}$ e cita o trabalho

100 SANTA LUCIA. Department of Sustainable Development,
Ministry of Education, Innovation, Gender Relations and Sustain-
able Development. Saint Lucia's National Adaption Plan: 2018-2028.
2018. p. 18. Disponível em: https://www4.unfccc.int/sites/NAPC/
Documents/Parties/SLU-NAP-May-2018.pdf. Acesso em: 20 jun.
2019. Traduzido a partir de: "[...] the impact of Hurricane Tomas (2010)
had a total cost of 43.4\% of the island's GDP. [...] Also, in 2013, an un-
seasonal low-level trongh system passed over the island and produced greater than
224 mm of rainfall in a matter of two to three hours. The system impacted
2,600 persons directly, killed 6, destroyed 47 homes and caused USD 89.2
million in damages."
101 SANTA LUCIA. Department of Sustainable Development, Ministry of Education, Innovation, Gender Relations and Sustainable Development. Saint Lucia's National Adaption Plan: 2018-2028. 2018. p. 18. Disponível em: https://www4.unfccc.int/sites/NAPC/ Documents/Parties/SLU-NAP-May-2018.pdf. Acesso em: 20 jun. 2019. Traduzido a partir de: "Relocation of critical infrastructure and communities, and associated costs and problems related to limited suitable areas. Increased costs of relocating, replacing and/or repairing infrastructure, which has been destroyed, dislocated or damaged."

102 SANTA LUCIA. Department of Sustainable Development, Ministry of Education, Innovation, Gender Relations and Sustainable Development. Saint Lucia's National Adaption Plan: 2018-2028. 2018. p. 126. Disponível em: https://www4.unfccc.int/sites/ NAPC/Documents/Parties/SLU-NAP-May-2018.pdf. Acesso em: 20 jun. 2019.

103 SANTA LUCIA. Department of Sustainable Development, Ministry of Education, Innovation, Gender Relations and Sustainable Development. Saint Lucia's National Adaption Plan: 2018-2028. 2018. p. 126. Disponível em: https://www4.unfccc.int/sites/ NAPC/Documents/Parties/SLU-NAP-May-2018.pdf. Acesso em: 20 jun. 2019. que vem sendo desenvolvido pelo Comitê Executivo do WIM com o intuito de melhor compreender não apenas o gerenciamento de riscos de cunho climático, mas também perdas econômicas e não econômicas, eventos de início lento, assim como processos de mobilidade humana relacionados ao fenômeno das alterações induzidas do clima. Nesse contexto, faz referência expressa à Força-Tarefa sobre Deslocamento ${ }^{104}$.

Assim posta a questão, percebe-se que os PNAs são instrumentos fundamentais para a integração da mobilidade humana nas estratégias nacionais de adaptação relacionadas aos efeitos adversos das mudanças climáticas, visto que "o delineamento de medidas pátrias de adaptação oportuniza que a migração, o deslocamento e a realocação planejada sejam devidamente abordados, levando-se em consideração possíveis desafios e oportunidades" ${ }^{105}$.

Nesse sentido, observa-se que todos os PNAs apresentados pelos países latino-americanos e caribenhos reconhecem, ainda que de forma genérica, as interconexões existentes entre os efeitos adversos das mudanças climáticas e fluxos populacionais em âmbito regional e/ ou nacional ${ }^{106}$. Destaca-se, aqui, o documento publicado por Santa Lúcia, o qual faz menção expressa não apenas à TFD, mas também ao trabalho que vem sendo desenvolvido pelo Comitê Executivo do WIM.

Apesar disso, ainda que o PNA do Brasil equipare processos migratórios à possíveis estratégias de adaptação, nenhum deles propõe medidas efetivas para a abordagem da temática, o que significa que desafios ainda persistem. Além da necessidade de envolvimento de assessoria técnica especializada sobre como a incorporação

104 SANTA LUCIA. Department of Sustainable Development, Ministry of Education, Innovation, Gender Relations and Sustainable Development. Saint Lucia's National Adaption Plan: 2018-2028. 2018. p. 126. Disponível em: https://www4.unfccc.int/sites/ NAPC/Documents/Parties/SLU-NAP-May-2018.pdf. Acesso em: 20 jun. 2019.

105 WARNER, Koko et al. National adaptation plans and human mobility. FMR Review, n. 49, maio 2015. Disponível em: https:// www.fmreview.org/sites/fmr/files/FMRdownloads/en/climatechange-disasters/warner-kaelin-martin-nassef.pdf Acesso em: 01 jul. 2019. Traduzido a partir de: "The national adaptation planning process provides an opportunity to ensure that migration, displacement and planned relocation are fully addressed, as well as potential challenges and potential opportunities."

106 YAMAMOTO, Lilian et al. Human mobility in the context of climate change and disasters: a South American approach. International Journal of Climate Change Strategies and Management, v. 10, n. 1, p. 65-85, 2018. p. 77. 
da mobilidade humana deve ser realizada em programas de adaptação formuladas por governos nacionais, o fornecimento de dados que precisem como as mudanças climáticas levam à processos migratórios — garantindo o estabelecimento de estratégias efetivas — também se mostram imprescindíveis ${ }^{107}$.

\subsection{A incorporação do tópico a partir das Contribuições Nacionalmente Determinadas (NDCs)}

As Contribuições Nacionalmente Determinadas (NDCs), chamadas de Contribuições Nacionalmente Determinadas Pretendidas (INDCs) até a ratificação do Acordo de Paris, descrevem, sobretudo, medidas de mitigação e adaptação propostas pelos Estados-Partes com vistas à redução de GEE na superfície terrestre, refletindo as ambições de cada país em âmbito doméstico ${ }^{108}$.

De acordo com o repositório da CQNUMC, 184 Estados-Partes oficializaram a submissão de suas NDCs até o momento ${ }^{109}$ : desse total, 21 países integram a América Latina ${ }^{110}$ e 13 fazem parte do Caribe ${ }^{111}$. A mobilidade bumana no contexto dos efeitos adversos das mudanças climáticas, entretanto, foi mencionada, de forma expressa, por apenas 05 nações latino-americanas — Equador,

\footnotetext{
107 WARNER, Koko et al. Integrating human mobility issues within National Adaptation Plans. Policy Brief, n. 9, jun. 2014. Disponível em: http://collections.unu.edu/eserv/UNU:1838/pdf11800.pdf. Acesso em: 01 jul. 2019.

108 Convém mencionar que as INDCs foram apresentadas pelos Estados-Partes da CQNUMC anteriormente à COP21 com o intuito de apoiar o estabelecimento de metas de mitigação legalmente vinculantes em âmbito internacional. Ou seja, a soma das contribuições nacionais inicialmente apresentadas serviria de base para a formulação de compromissos globais para o combate das mudanças climáticas. Com a adoção do Acordo de Paris, em dezembro de 2015, as INDCs tornam-se automaticamente NDCs quando da ratificação pelo Estado-Membro, a menos que esse decida submeter novas metas no momento da assinatura. ORGANIZAÇ̃̃O INTERNACIONAL PARA AS MIGRAÇÕES. Migration in INDCs/ NDCs. Suíça: IOM, 2016. Disponível em: https://environmentalmigration.iom.int. Acesso em: 24 jun. 2019.

109 UNITED NATIONS. NDC Registry. Disponível em: https:/ / www4.unfccc.int/sites/NDCStaging/Pages/All.aspx. Acesso em: 20 jun. 2019.

110 São eles: Argentina, Belize, Bolívia, Brasil, Chile, Colômbia, Costa Rica, El Salvador, Equador, Guatemala, Guiana, Guiana Francesa, Honduras, México, Nicarágua, Panamá, Paraguai, Peru, Suriname, Uruguai e Venezuela.

111 São eles: Antígua e Barbuda, Bahamas, Barbados, Cuba, Dominica, Granada, Haiti, Jamaica, República Dominicana, Santa Lúcia, São Cristóvão e Nevis, São Vicente e Granadinas, Trinidade e Tobago.
}

Colômbia, México, Suriname e Uruguai ${ }^{112}$ - e por 1 estado caribenho - Haiti.

O primeiro registro do tema advém da NDC do México, submetida em 2016. O documento apresenta como uma de suas prioridades a proteção de comunidades vulneráveis às mudanças climáticas por meio do fortalecimento da capacidade adaptativa. Para tanto, inclui ações concretas de adaptação a serem implementadas entre 2020 e 2030, tais como a "realocação de assentamentos humanos irregulares situados em áreas propensas a desastres por meio da regulamentação e uso adequado da terra" $"$.113.

Por sua vez, o Haiti, cuja NDC foi apresentada à CQNUMC em 2017, insere a mobilidade humana em razão das alterações induzidas do clima como uma estratégia de adaptação. O governo haitiano evidencia não apenas a necessidade de integração entre pessoas que se deslocam tanto dentro quanto fora de suas fronteiras nacionais, mas também a imprescindibilidade de se estabelecerem projetos de realocação planejada, os quais reduziriam o risco de desastres em áreas vulneráveis. Outrossim, almeja o "desenvolvimento e implementação de planejamento urbano" capazes de evitar o fluxo temporário de indivíduos expostos a inundações ${ }^{114}$.

No mesmo ano, a carta de intenções do Uruguai fez referência ao Plano Nacional de Realocação, programa adotado em 2010 pelo país com o intuito de reassentar famílias desprovidas de recursos financeiros e que habitam áreas de risco. Segundo a NDC, o plano nacional realocou 1.715 famílias entre 2010 e 2016, prevendo, ainda, a transferência de outras 2.500 até 2020. Para além disso, o governo uruguaio pretende, até 2025,

112 Apesar de a INDC apresentada pela Venezuela em dezembro de 2015 ter feito menção ao programa Gran Misión Vivienda como resposta às chuvas excessivas que inundaram largas extensões de terras e afetaram milhares de habitantes de regiões vulneráveis em 2010, a NDC apresentada pela nação em 2018 nada menciona quanto ao assunto. REPUBLICA BOLIVARIANA DE VENEZUELA. Contribuciones Previstas Nacionalmente Determinadas de la República Bolivariana de Venezuela para la lucha contra el Cambio Climático y sus efectos. 2015. Disponível em: https://www4.unfccc.int/sites/NDCStaging/Pages/All.aspx. Acesso em: 25 jun. 2019.

113 ESTADOS UNIDOS MEXICANOS. Intended Nationally Determined Contribution. 2016. p. 6. Disponível em: https://www4.unfccc. int/sites/NDCStaging/Pages/All.aspx. Acesso em: 25 jun. 2019. Traduzido a partir de: "[...] relocate irregular human settlements in zones prone to disasters through land use regulations."

114 REPUBLIQUE D'HAÏTI. Contribution Prérue Déterminée au niveau National. 2017. Disponível em: https://www4.unfccc.int/ sites/NDCStaging/Pages/All.aspx Acesso em: 05 jul. 2019. Traduzido a partir de: "[...] élaboration et mise en cuvre de Plans d'urbanisme." 
[...] realocar entre 3.500 e 6.000 famílias localizadas em zonas propensas à inundações e/ou contaminações e que foram previamente identificadas pelo Plano Nacional de Realocação ou por outros instrumentos nacionais, garantindo a essa população o acesso a serviços básicos e atribuindo novos usos às zonas de inundação ${ }^{115}$.

Já a NDC colombiana, disponibilizada em 2018, aborda fluxos migratórios a partir do processo de pacificação que vem sendo conduzido no país. Nesses termos, tem-se que:

O desenvolvimento da paz na Colômbia apresenta
desafios econômicos, sociais e ambientais para
o país. [...] No passado, processos de pacificação
em diversas regiões do globo têm sido associados
a impactos negativos no meio ambiente, devido,
dentre outros, a processos migratórios que
acentuam a pressão sobre recursos naturais em
áreas vulneráveis ${ }^{116}$.

Em fevereiro de 2019, por meio da sua NDC, o Suriname reconhece a vulnerabilidade de sua zona costeira, assim como o aumento significativo da população que se encontra exposta aos efeitos adversos das mudanças climáticas em tais localidades. À vista disso, ressalta a necessidade de investimentos para a realocação de comunidades ameaçadas pela possível elevação do nível do mar e, concomitantemente, expressa sua preocupação com os impactos que tais processos migratórios podem ocasionar, como o desmatamento de áreas florestadas ${ }^{117}$.

Por fim, o Equador tornou sua NDC pública em março de 2019. Em síntese, essa almeja o estabelecimento de parâmetros que permitam o desenvolvimento de políticas que lidem com processos migratórios rela-

115 ORIENTAL REPUBLIC OF URUGUAY. First Nationaly Determined Contribution to the Paris Agreement. 2017. Disponível em: https://www4.unfccc.int/sites/NDCStaging/Pages/All.aspx. Acesso em: 25 jun. 2019. Traduzido a partir de: "To have relocated, by 2025, between 3500 and 6000 of the households in flood or contaminated zones identified through the National Relocation Plan and other national and departmental instruments, enabling access to basic services to relocated population and assigning new uses to give a different significance to flood zones."

116 COLOMBIA. Intended Nationally Determined Contribution. 2018. Disponível em: https://www4.unfccc.int/sites/NDCStaging/Pages/All.aspx. Acesso em: 25 jun. 2019. Traduzido a partir de: "Building peace in Colombia presents economic, social and environmental challenges for the country. [...] In the past, peace processes elsewhere in the world have been associated with negative impacts on the environment, due to, among other things, migration patterns that increase pressure on natural resources in the most vulnerable areas."

117 REPUBLIC OF SURINAME. Intended Nationaly Determined Contribution Under UNFCCC. 2015. Disponível em: https://www4. unfccc.int/sites/NDCStaging/Pages/All.aspx. Acesso em: 25 jun. 2019. cionados às mudanças climáticas - sejam eles de caráter temporário ou permanente — de modo a enquadrá-los como estratégias adaptativas ${ }^{118}$.

Isso posto, percebe-se que as referências à mobilidade bumana feitas nas NDCs apresentadas pelos países da América Latina e do Caribe, resguardadas as suas peculiaridades, refletem os debates internacionais sobre o tema, concentrando-se em dois aspectos principais.

Além do reconhecimento de que fluxos populacionais podem resultar dos efeitos adversos das mudanças climáticas, destaca-se que a mobilidade humana decorrente de tais fenômenos precisa ser enfrentada de forma preventiva. Nesse sentido, com exceção da Colômbia, as demais nações que abordam o tópico apresentam e/ ou salientam a necessidade de programas de reassentamento para melhor gerenciar o deslocamento forçado de indivíduos ${ }^{119}$. Isto é, processos migratórios são incentivados como estratégias adaptativas e materializar-se-iam com base em programas de realocação planejada, pressupondo, portanto, a assistência dos governos locais $^{120}$.

Haja vista que essa categoria de mobilidade humana requer fundos substanciais, indaga-se como tais processos são e/ou serão financiados: sabe-se que as nações mais afetadas pela deterioração do meio ambiente acabam sendo aqueles com alto grau de vulnerabilidade e, logo, com menor poder político. Ademais, ainda que a realocação de aglomerados humanos que habitam regiões vulneráveis aos efeitos adversos das mudanças climáticas possa parecer óbvia, inúmeras questões práticas e éticas permanecem sem respostas, tais como "de que forma lida com a remoção de populações que não consentem com tal processo? Que porções de terra devem ser alocadas para esses indivíduos? Quais os critérios de escolha e tais áreas? Quando a transferência deve ocorrer?"121.

118 REPÚBLICA DEL ECUADOR. Primera Contribución Determinada a Nivel Nacional para el Acuerdo de París bajo la Convención Marco de Naciones Unidas sobre Cambio Climático. 2019. Disponível em: https:/ / www4.unfccc.int/sites/NDCStaging/Pages/All.aspx. Acesso em: 20 ago. 2019.

119 YAMAMOTO, Lilian et al. Human mobility in the context of climate change and disasters: a South American approach. International Journal of Climate Change Strategies and Management, v. 10, n. 1, p. 65-85, 2018. p. 77.

120 ORGANIZAÇÃO INTERNACIONAL PARA AS MIGRAÇÕES. Migration in INDCs/NDCs. Suíça: IOM, 2016. Disponível em: https://environmentalmigration.iom.int. Acesso em: 24 jun. 2019.

${ }^{121}$ IONESCO, Dina; MOKHNACHEVA, Daria; GEMENE, 
As respostas variam de caso a caso e os programas colocados em prática até o momento apresentam resultados mistos: "apesar de reduzir o número de seres humanos expostos a riscos ambientais, outras fragilidades emergem, como o esfacelamento de redes sociais e a perda de recursos econômicos"122. Resta saber, diante disso, como o tema deste estudo é abordado com base em políticas nacionais de cunho climático.

\subsection{A incorporação do tópico a partir de políticas nacionais de cunho climático}

Inúmeras leis nacionais que regulamentam questões associadas às mudanças climáticas podem ser identificadas nos países que compõem a América Latina e a região do Caribe. Contudo, convém mencionar que, em relação as 34 nações cujas legislações pátrias foram analisadas ${ }^{123}$, apenas 5 apresentam disposições relacionadas à temática da presente pesquisa: Costa Rica, México, Ni-

François. The Atlas of environmental migration. London and New York: Routledge - Taylor and Francis Group, 2017. p. 27. Traduzido a partir de: “[... should populations be displaced against their wishes? What kind of compensation should be envisaged? What land can be allocated to those relocated? How should the relocation site be chosen? When should relocation take place?"

122 IONESCO, Dina; MOKHNACHEVA, Daria; GEMENE, François. The Atlas of environmental migration. London and New York: Routledge - Taylor and Francis Group, 2017. p. 27. Traduzido a partir de: "[...] while they have indeed helped to reduce the number of people exposed to environmental risks, other weaknesses have appeared, linked to the dislocation of social networks and to the loss of economic resources [...]."

123 As legislações nacionais voltadas às alterações induzidas do clima dos seguintes países foram verificadas: Bahamas (Politica Nacional para a Adaptação à Mudança Climática de 2005), Brasil (Política Nacional sobre Mudança Climática - Lei n. 12.187 de 2009), Colômbia (Política Nacional sobre Mudança Climática de 2017), Costa Rica (Política Nacional sobre Adaptação à Mudança Climática 2018-2030 - Decreto n. 20 de 2018), Guatemala (Política Nacional sobre Mudança Climática - Acordo Governamental n. 329 de 2009 e Lei Marco para a regularização da redução da vulnerabilidade, da adaptação aos efeitos da mudança climática e da mitigação de GEE - Decreto n. 07 de 2013), Honduras (Lei sobre Mudança Climática - Decreto n. 297 de 2013), Jamaica (Política e Plano de Ação sobre Mudança Climática de 2013), Panamá (Politica Nacional sobre Mudança Climática - Decreto n. 35 de 2007), Paraguai (Política Nacional sobre Mudança Climática e Lei Nacional sobre Mudança Climática - Lei n. 5.875 de 2017), República Dominicana (Política Nacional sobre Mudança Climática - Decreto n. 278 de 2013 e Decreto n. 269 de 2015), Santa Lucia (Política sobre Adaptação à Mudança Climática de 2015) e Trinidade e Tobago (Política Nacional sobre Mudança Climática de 2011). Antígua e Barbuda, Argentina, Barbados, Belize, Bolívia, Chile, Cuba, Dominica, El Salvador, Equador, Granada, Guiana, Guiana Francesa, Haiti, São Cristóvão e Nevis, São Vicente e Granadinas, Suriname e Venezuela possuem apenas estratégias nacionais ou planos de ação para lidar com os efeitos adversos das mudanças do clima, sem dispor de políticas nacionais devidamente regulamentadas pelo Poder Legislativo pátrio. carágua, Peru e Uruguai.

Inicialmente, tem-se a Politica Nacional sobre Mudança Climática do Uruguai, regulamentada pelo Decreto $\mathrm{n}$. 310 de 2017. Ao instituí-la, buscou-se "contribuir para o desenvolvimento sustentável do país, com uma perspectiva global, pautada na equidade e nos direitos humanos intra e intergeracionais, almejando uma sociedade mais resiliente e menos vulnerável, com uma maior capacidade adaptativa" ${ }^{\prime 24}$.

Além de trazer uma abordagem pautada em garantias que permeiam a dignidade da pessoa humana, a Política uruguaia, ao dispor sobre os aspectos sociais, sublinha a necessidade da elaboração de programas capazes de promover a realocação de comunidades que habitam "zonas de risco climático", assim como de formulação de mecanismos capazes de "capacitar a sociedade, em particular as populações mais vulneráveis, para conhecer os riscos das mudanças e variabilidades climáticas, possibilitando a interpretação adequada dos sistemas de alerta antecipados" ${ }^{125}$. Verifica-se, portanto, um enfoque nas capacidades adaptativa e de resiliência.

\section{É, no entanto, a Lei-Marco sobre Mudança Climática do} Peru, promulgada 2018, por meio do Decreto Legislativo n. 30.754, merece destaque nesta pesquisa. Isso porque se trata da primeira lei de cunho climático a abordar, de forma efetiva, a mobilidade humana no contexto das variações induzidas do clima em âmbito regional.

O governo peruano adotou uma terminologia particular para representar tais indivíduos, usando o termo migrante ambiental para designar quaisquer pessoas ou grupo de pessoas que, "em virtude de alterações ambientais inevitáveis, repentinas ou progressivas, que afetam negativamente as condições de vida, são forçados a abandonar seus locais de residência habitual, ou fazem-no de forma voluntária". A definição acrescen-

124 REPÚBLICA ORIENTAL DEL URUGUAY. Politica Nacional de Cambio Climático. 2017. Disponível em: https://www.undp.org/... Acesso em: 05 jul. 2019. Traduzido a partir de: "La Política debe contribuir al desarrollo sostenible del país, con una perspectiva global, de equidad intra e intergeneracional y de derechos bumanos, procurando una sociedad más resiliente, menos vulnerable, con mayor capacidad de adaptación al cambio y a la variabilidad climática."

125 REPÚBLICA ORIENTAL DEL URUGUAY. Politica Nacional de Cambio Climático. 2017. Disponível em: https://www.undp.org/... Acesso em: 05 jul. 2019. Traduzido a partir de: "Profundizar las estrategias de relocalización de población vulnerable que babita en zonas de riesgos climáticos." e "Incrementar la capacidad de la sociedad, en particular de la población más vulnerable de conocer los riesgos del cambio y la variabilidad climática y de acceder e interpretar adecuadamente a los sistemas de alerta temprana." 
ta, ainda, que o “deslocamento poderá ser temporário ou permanente, dentro de seu país ou no exterior" ${ }^{126}$, aproximando-se do conceito disponibilizado pela OIM em 2007, anteriormente mencionado.

Além disso, a Lei-Marco chama atenção para os fluxos populacionais provocados por adversidades ambientais e prevê a elaboração de um plano de ação, ainda em fase de elaboração, para prevenir e lidar com os impactos negativos das alterações induzidas do clima. Caberá, desse modo,

\begin{abstract}
ao Poder Executivo emitir um plano de ação para prevenir e responder aos processos migratórios forçados causados pelos efeitos das mudanças climáticas, evitando a sobrecarga da infraestrutura e de serviços urbanos, o aumento de conflitos sociais, bem como o declínio de indicadores sociais relacionados à educação e à saúde ${ }^{127}$.
\end{abstract}

Por sua vez, ao estabelecer a Politica Nacional sobre Adaptação à Mudança Climática 2018-2030, por meio do Decreto n. 20 de 2018, a Costa Rica salientou que a interferência do homem na superfície terrestre "envolve inúmeros riscos que podem prejudicar os direitos humanos, desde ameaças à saúde até danos à propriedade privada, incluindo os meios de subsistência e a cultura de grupos mais vulneráveis". À vista disso, aduz que a “adaptação às mudanças do clima só será alcançada se o direito à saúde, à água potável, à alimentação adequada e à habitação digna forem garantidos" ${ }^{128}$.

O documento destaca duas modalidades que compõem o conceito de mobilidade humana, conforme ana-

126 PERU. Ley Marco sobre Cambio Climático. 2018. Disponível em: https://www.undp.org/... Acesso em: 05 jul. 2019. Traduzido a partir de: "Personas o grupos de personas que por culpa de cambios medioambientales ineludibles, súbitos o progresivos, que afectan de forma negativa sus vidas o sus condiciones de vida, se ven obligadas a dejar sus hogares habituales, o deciden hacerlo voluntariamente. El desplazamiento puede ser temporal o permanente, en el interior de su país o en el extranjero."

127 PERU. Ley Marco sobre Cambio Climático. 2018. Disponível em: https://www.undp.org/... Acesso em: 05 jul. 2019. Traduzido a partir de: "El Poder Ejecutivo emitirá un plan de acción para prevenir y atender la migración forzosa causada por los efectos del cambio climático, a fin de evitar el incremento de la presión sobre las infraestructuras y servicios urbanos, el aumento de la posibilidad de conflictos sociales y, entre los mismos migrantes, el detrimento de los indicadores sanitarios, educativos y sociales."

128 COSTA RICA. Politica Nacional de Adaptación al Cambio Climático de Costa Rica (2018-2030). 2018. Disponível em: http://www.pgrweb. go.cr/DocsDescargar/Normas/... Acesso em: 05 jul. 2019. Traduzido a partir de: "[...] conlleva diversos riesgos que pueden afectar los derechos humanos, desde las amenazas para la salud hasta los daños sobre propiedades, medios de subsistencia e incluso culturas de los grupos más vulnerables." e "Desde un enfoque de derechos humanos, la adaptación al cambio climático solo se logrará si se aseguran los derechos a la salud, al agua potable, a una alimentación adecuada y a una vivienda digna." lisado previamente: "as mudanças climáticas também afetarão as populações que serão forçadas a se deslocar no interior do país ou, ainda, a migrar fora desse, acarretando consequências em termos humanitários" ${ }^{\text {129. }}$.

Não menos importante, em 2018, o governo mexicano aprovou reformas na sua Lei Geral sobre Mudança Climática, em vigor desde 2012. Além de declarar que o Estado deverá observar os direitos humanos dos migrantes ao lidar com questões de natureza climática ${ }^{130}$, a Lei Geral realça que a ocorrência de fluxos migratórios deve ser considerada para elaboração de todas as políticas públicas que envolvem as alterações induzidas do clima, possibilitando a prevenção, pelas entidades administrativas da federação, de deslocamentos internos causados por eventos extremos ${ }^{131}$.

Nesse contexto, programas de reassentamento planejado estariam dentre as estratégias adaptativas a serem implementadas pelo México, havendo que se falar no estabelecimento de "mecanismos de coleta e obtenção de recursos — ainda em fase de regulamentação — a serem utilizados para a proteção e a realocação dos assentamentos humanos que são mais vulneráveis aos efeitos adversos das mudanças climáticas" ${ }^{\text {"132. }}$.

Como último país a ser analisado, tem-se a Nicarágua, que instituiu, a partir da publicação do Decreto Presidencial n. 27 de 2019, a Politica Nacional sobre Mitigação e Adaptação à Mudança Climática e a Criação do Sistema Nacional de Resposta à Mudança Climática. Ao elencar os principais avanços nacionais em matéria de adaptação, o documento descreve a assistência concedida às famí-

129 COSTA RICA. Política Nacional de Adaptación al Cambio Climático de Costa Rica (2018-2030). 2018. Disponível em: http://www.pgrweb. go.cr/DocsDescargar/Normas/... Acesso em: 05 jul. 2019. Traduzido a partir de: "El cambio climático también afectará a poblaciones que se verán obligadas a desplazarse en el interior del país, o a migrar fuera de este, con consecuencias en materia de derecho bumanitario."

130 ESTADOS UNIDOS MEXICANOS. Ley General de Cambio Climático: Nueva Ley publicada en el Diario Oficial de la Federación de 6 de Junio de 2012. 2018. Disponível em: https://www.gob.mx/. Acesso em: 05 jul. 2019.

131 ESTADOS UNIDOS MEXICANOS. Ley General de Cambio Climático: Nueva Ley publicada en el Diario Oficial de la Federación de 6 de Junio de 2012. 2018. Disponível em: https://www.gob.mx/. Acesso em: 05 jul. 2019.

132 ESTADOS UNIDOS MEXICANOS. Ley General de Cambio Climático: Nueva Ley publicada en el Diario Oficial de la Federación de 6 de Junio de 2012. 2018. Disponível em: https://www.gob.mx/. Acesso em: 05 jul. 2019. Traduzido a partir de: "Proponer e impulsar mecanismos de recaudación y obtención de recursos, para destinarlos a la protección y reubicación de los asentamientos humanos más vulnerables ante los efectos del cambio climático; [....." 
lias afetadas por eventos extremos. Em resposta às adversidades ambientais que assolaram o país no período compreendido entre 2007 e 2011, o governo afirma ter amparado cerca de 131.700 famílias, isto é, aproximadamente 697.008 indivíduos que representam $11.6 \%$ de toda a população nicaraguense ${ }^{133}$.

Pelo exposto, denota-se que, aos poucos, os países latino-americanos e caribenhos começam a reconhecer e a integrar em suas agendas nacionais do clima a mobilidade humana decorrente das mudanças climáticas. Ao passo que a reformulação da política nacional mexicana sobre as alterações induzidas do clima possibilitou o reconhecimento e a assimilação da temática, a instituição de uma nova política climática peruana já estava ciente da necessidade de abordá-la, trazendo, inclusive, uma definição para os chamados migrantes ambientais.

Isso não significa, contudo, que soluções efetivas como o estabelecimento de planos de ação e de estratégias de prevenção e proteção - tenham sido propostas e/ou implementadas, ainda que haja indicação expressa dessa necessidade em alguns contextos nacionais, como verificado acima.

Por fim, deve-se mencionar que grande parte da legislação analisada antecede o Acordo de Paris, momento em que o tema da mobilidade humana no contexto das mudanças climáticas foi oficialmente incorporado pelo regime climático internacional. Todos os cinco países que incorporaram a questão até o momento - Costa Rica, México, Nicarágua, Peru e Uruguai - estabeleceram ou reformularam suas políticas nacionais climáticas a partir de 2017, ou seja, após a implementação e o início das atividades da Força-Tarefa sobre Deslocamento. A expectativa a partir de agora é que outros países, com base na constatação de que mobilidade humana decorrente do aquecimento global pode gerar significativos distúrbios sociais, econômicos e ambientais, passem a também considerar o tema em suas respectivas políticas nacionais.

133 REPÚBLICA DE NICARAGUA. Decreto para establecer la Politica Nacional de Mitigación y Adaptación al Cambio Climático y de creación del Sistema Nacional de Respuesta al Cambio Climático. 2019. Disponível em: http://legislacion.asamblea.gob.ni/. Acesso em: 05 jul. 2019.

\section{Considerações finais}

Atentou-se, de início, para o fato de que a alteração da composição da superfície do planeta não significa que as mudanças climáticas possam ser descritas como uma nova causa de mobilidade humana. Ao contrário, as alterações induzidas do clima não se caracterizam como o único responsável pela constante redistribuição geográfica na atualidade.

Além de se enfatizar os dados apresentados pelo IDMC com o intuito de dimensionar a problemática, diante da multiplicidade de nomenclaturas utilizadas para descrever aqueles que se deslocarão em razão dos efeitos adversos das mudanças climáticas, a presente pesquisa optou pelo uso do termo mobilidade buma$n a$, concepção mais consensual e capaz de abranger as nuances das diversas situações que se apresentam em âmbito internacional.

A contextualização das particularidades que permeiam o tema possibilita a melhor compreensão da razão pela qual inexiste um regime jurídico próprio, com normas e princípios que reconheçam e tutelem todos aqueles sujeitos à mobilidade humana.

Quanto à análise do tema a partir do regime climático internacional, observou-se que, apesar dos avanços observados no decorrer da última década, essa esfera de governança não dispõe de instrumentos jurídicos capazes de lidar com os fluxos populacionais que decorrem dos efeitos adversos das mudanças climáticas. Até o momento, há, apenas, o reconhecimento da urgência de medidas a fim de se conferir um tratamento adequado e digno a essas pessoas.

Ao correlacionar as evidências que conectam mobilidade humana às mudanças climáticas a partir das recomendações formuladas pela TFD, observou-se que a agenda internacional do clima pode vir a oportunizar reformas na governança global contemporânea, trazendo maior visibilidade à questão.

Ainda que de forma lenta, sublinhou-se que o sistema da CQNUMC começa não apenas a reforçar a imprescindibilidade da adoção de medidas concretas para o tema, mas também a moldar as bases para uma futura estrutura jurídica. Nesse sentido, o WIM pode vir a fornecer ferramentas valiosas para resolver o embate: resta aguardar o direcionamento dos debates políticos sobre o assunto nos próximos cinco anos. 
No que tange à assimilação do tópico pelas nações que compõem a América Latina e a região do Caribe, averiguou-se que os PNAs e as NDCs submetidos até o momento não são suficientemente aproveitados e/ ou explorados. Não obstante mencionem a mobilidade humana no contexto das variações induzidas do clima, tais instrumentos não consideram os desafios inerentes ao tópico de forma adequada, é dizer, esses não estabelecem providências capazes de prevenir e responder ao problema de forma eficaz.

Em relação aos 04 PNAs analisados, destacou-se o plano do Brasil por equiparar processos migratórios à possíveis estratégias de adaptação, assim como o documento publicado por Santa Lúcia, o qual faz menção expressa não apenas à TFD, mas também ao trabalho que vem sendo desenvolvido pelo Comitê Executivo do WIM em matéria de migração, deslocamentos e realocações planejadas associados às mudanças do clima.

Muito embora os 34 países latino-americanos e carinhos tenham submetido suas NDCs à CQNUMC, contatou-se que a mobilidade humana no contexto dos efeitos adversos das mudanças climáticas foi mencionada, de forma expressa, por apenas 06 deles. Resguardadas as suas peculiaridades, todas refletem os debates internacionais sobre o tema, enfatizando dois aspectos principais: além do reconhecimento de que fluxos populacionais podem ser provocados pelas variações induzidas do clima, tais deslocamentos devem ocorrer de forma preventiva e/ ou antecipatória. Com a exceção da Colômbia - que relaciona o tema ao processo de pacificação no território nacional —, processos migratórios são incentivados como medidas adaptativas e materializar-se-iam com base em programas de reassentamento.

Apurou-se, ainda, que, a respeito das 34 nações cujas legislações pátrias de cunho climático foram analisadas, apenas 05 apresentam disposições relacionadas à temática desta pesquisa. Percebeu-se que a incorporação da matéria nas políticas climáticas em âmbito nacional passou a ser verificada, somente, a partir da assinatura do Acordo de Paris, em 2015, momento em que ações concretas para a melhor compreensão da mobilidade humana por essa esfera de governança foram determinadas.

Notou-se que, em geral, tratam-se de referências abstratas, sem especificar planos que possam gerenciar e assistir àqueles que integram fluxos populacionais engendrados pelos efeitos adversos das mudanças climáticas. Além da assimilação do tema a partir da refor- mulação da Lei Geral sobre Mudança Climática do México, destacou-se a Lei-Marco sobre Mudança Climática do Peru, a qual define migrante ambiental e prevê a elaboração de um plano de ação para lidar com a temática, ainda em fase de elaboração.

Pelo exposto, sugere-se a revisão das legislações existentes ou, ainda, a elaboração de novas normas voltadas às mudanças climáticas que levem em consideração as interconexões existentes entre os impactos negativos desse fenômeno e a mobilidade humana, possibilitando o fortalecimento de políticas nacionais a partir da sua aproximação a diretrizes e recomendações internacionais sobre a questão. Além do suporte jurídico, há de se falar, ainda, na assistência institucional e no apoio financeiro por parte dos governos nacionais, garantindo, desse modo, a efetivação de tais estratégias normativas.

\section{Referências}

ADVISORY GROUP ON HUMAN MOBILITY AND CLIMATE CHANGE. Human mobility in the context of climate change: Elements for the UNFCCC Paris Agreement. Suíça: IOM, 2015.

BEHRMAN, Simon; KENT, Avidan. Overcoming the legal impasse? Setting the scene. In: BEHRMAN, Simon; KENT, Avidan. Climate Refugees: beyond the legal impasse? EUA: Routledge Studies in Environmental Migration, Displacement and Resettlement, 2018.

BODANSKY, Daniel; BRUNNÉE, Jutta; RAJAMANI, Lavanya. International climate change law. Oxford, UK: Oxford University Press, 2017.

BODANSKY, Daniel; BRUNNÉE, Jutta; RAJAMANI, Lavanya. The history of the global climate change regime. In: LUTERBACHER, U.; SPRINZ, D. F. (edit.). International relations and global climate change. Cambridge: MIT Press, 2001.

BRADBROOK, Adrian J.; OTTINGER, Richard L. Energy law and sustainable development. Geneva, Switzerland: IUCN, 2003.

BRASIL. Ministério do Meio Ambiente. Acordo de Paris. Disponível em: https://www.mma.gov.br/clima/ convencao-das-nacoes-unidas/acordo-de-paris Acesso em: 15 dez. 2018.

BRASIL. Ministério do Meio Ambiente. Plano Nacional 
de Adaptação à Mudança do Clima: Volume 1 - Estratégia Geral. 2016. Disponível em: http://www.pbmc.coppe. ufrj.br/documentos/PNA-Volume1.pdf Acesso em: 20 jun. 2019.

BRASIL. Ministério do Meio Ambiente. Plano Nacional de Adaptação à Mudança do Clima: Volume 2 - Estratégia Setoriais e temáticas. 2016. Disponível em: https:// www.mma.gov.br/images/arquivo/80182/LIVRO_ PNA_Plano\%20Nacional_V2.pdf Acesso em: 20 jun. 2019.

BURKETT, Maxine. Justice and climate migration: the importance of nomenclature in the discourse on twenty-first-century mobility. In: BEHRMAN, Simon; KENT, Avidan. Climate Refugees: beyond the legal impasse? EUA: Routledge Studies in Environmental Migration, Displacement and Resettlement, 2018.

CAMPBELL, John. Climate-induced community relocation in the Pacific: the meaning and importance of land. In: MCADAM, Jane. Climate change and displacement. Multidisciplinary Perspectives. Portland, EUA: Hart Publishing, 2010.

CAPDEVILLE, Fernanda de Salles Cavedon. A mobilidade humana na agenda global do clima: uma questão de justiça climática. In: LEITE, José Rubens Morato; DINNEBIER, Flávia França (org.). Estado de Direito Ecológico: Conceito, conteúdo e novas dimensões para a proteção da natureza. São Paulo: Instituto O Direito por um Planeta Verde, 2017.

CARVALHO, Fernanda Viana de. Assuntos estratégicos: adaptação à mudança do clima: o quadro das negociações internacionais. Brasília: Secretaria de Assuntos Estratégicos da Presidência da República, 2014.

CHILE. Ministerio del Medio Ambiente. Plan Nacional de Adaptación al Cambio Climático. 2017. Disponível em: https://www4.unfccc.int/sites/.... Acesso em: 10 jun. 2019.

COLOMBIA. Departamento Nacional de Planeación. Plan Nacional de Adaptación al Cambio Climático. 2018. Disponível em: https://www4.unfccc.int/sites/NAPC/ Documents/Parties/Colombia... Acesso em: 20 jun. 2019.

COLOMBIA. Intended Nationally Determined Contribution. 2018. Disponível em: https://www4.unfccc.int/sites/ NDCStaging/Pages/All.aspx. Acesso em: 25 jun. 2019.

COSTA RICA. Politica Nacional de Adaptación al Cambio
Climático de Costa Rica (2018-2030). 2018. Disponível em: http://www.pgrweb.go.cr/DocsDescargar/Normas/... Acesso em: 05 jul. 2019.

ESTADOS UNIDOS MEXICANOS. Intended Nationaly Determined Contribution. 2016. Disponível em: https:/ / www4.unfccc.int/sites/NDCStaging/Pages/All.aspx. Acesso em: 25 jun. 2019.

ESTADOS UNIDOS MEXICANOS. Ley General de Cambio Climático: Nueva Ley publicada en el Diario Oficial de la Federación de 6 de Junio de 2012. 2018. Disponível em: https://www.gob.mx/. Acesso em: 05 jul. 2019.

EXECUTIVE COMMITTEE OF THE WARSAW INTERNATIONAL MECHANISM FOR LOSS AND DAMAGE ASSOCIATED WITH CLIMATE CHANGE IMPACTS. Technical Meeting: Action Area 6 - Migration, Displacement and Human Mobility. Casablanca, Marrocos: IOM, 2016.

FERNANDES, Elizabeth Alves. Meio ambiente e direitos humanos: o deslocamento de pessoas por causas ambientais agravadas pelas mudanças climáticas. Curitiba: Juruá, 2014.

GEMENE, François. Environmental Migration. In: MARTINIELLO, Marco; RATH, Jan. An introduction to international migration studies: European Perspectives. Amsterdam, Holanda: Amsterdam University Press, 2012. p. $238-257$.

HASTRUP, Kirsten; OLWIG, Karen F. Introduction: Climate change and human mobility. In: HASTRUP, Kirsten; OLWIG, Karen F. Climate change and human mobility: Global Challenges to the Social Sciences. Londres, UK: Cambridge University Press, 2012.

HETHERINGTON, Renée. Living in a dangerous climate: climate change and human evolution. Nova Iorque, EUA: Cambridge University Press, 2012.

INTERGOVERNMENTAL PANEL ON CLIMATE CHANGE. Climate change: The 1990 and 1992 IPCC Assessments. IPCC First Assessment Report Overview and Policymaker Summaries and 1992 IPCC Supplement. Canada, 1990.

INTERGOVERNMENTAL PANEL ON CLIMATE CHANGE. Global Warming of $1,5^{\circ} \mathrm{C}$ : an IPCC special report on the impacts of global warming of $1,5^{\circ} \mathrm{C}$ above pre-industrial levels and related global greenhouse gas emission pathways, in the context of strengthening 
the global response to the threat of climate change, sustainable development, and efforts to eradicate poverty. República da Coréia: Summary for Policymakers, 2018.

INTERGOVERNMENTAL PANEL ON CLIMATE CHANGE. Working Group I Contribution To The IPCC Fifth Assessment Report. Climate Change 2013: the Physical Science Basis. Sweden: 2013.

INTERNAL DISPLACEMENT MONITORING CENTRE. 2019 Global Report on Internal Displacement (GRID 2019). Genebra, Suíça: IDMC/NRC, 2019.

IONESCO, Dina; MOKHNACHEVA, Daria; GEMENE, François. The Atlas of environmental migration. London and New York: Routledge - Taylor and Francis Group, 2017.

JAKOBSSON, Elin. Norm formalization in International Policy Cooperation. In: BEHRMAN, Simon; KENT, Avidan. Climate Refugees: beyond the Legal impasse? EUA: Routledge Studies in Environmental Migration, Displacement and Resettlement, 2018.

KAZMI, Shakeel. Climate change: human rights in the times of climate displacement. Tese (Doutorado) - Elisabeth Haub School of Law, Pace University, White Plains, EUA, 2012.

LEAL-ARCAS, Rafael. Climate change and international trade. Cheltenham, UK: Edward Elgar Publishing Limited, 2013.

MATTOOS, Ana Carolina Barbosa Pereira; MONT'ALVERNE, Tarim Cristino Frota. O regime internacional do clima e a proteção aos "refugiados climáticos": quais desafios da COP21? Revista de Direito Internacional, Brasília, v. 13, n. 2, 2016.

MAYER, Benoit. The concept of climate migration: advocacy and its prospects. Cheltenham, UK: Edward Elgar Publishing Limited, 2016.

MAYER, Benoit. Who are 'climate refugees? Academic engagement in the post-truth era. In: BEHRMAN, Simon; KENT, Avidan. Climate Refugees: beyond the Legal Impasse? EUA: Routledge Studies in Environmental Migration, Displacement and Resettlement, 2018.

MAZZUOLI, Valério de Oliveira. Curso de Direito Internacional Público. São Paulo: Revista dos Tribunais, 2010.

MCADAM, Jane. Climate change, forced migration and international law. Oxford, UK: Oxford University Press, 2012.
MCLEMAN, Robert A. Climate and human migration: past experiences, future challenges. Nova Iorque, EUA: Cambridge University Press, 2014.

MYERS, Norman. Environmental exodus: an emergent crisis in the global arena. Washington: Project of the Climate Institute, 1995.

MYERS, Norman. Environmental refugees: an emergent security issue. Praga: Oxford University, U.K., 2005.

NICHOLSON, Calum T. M. Climate-induced migration: ways forward in the face of an intrinsically equivocal concept. In: MAYER, Benoît; CRÉPEAU, François. Research Handbook on Climate Change, Migration and the Law. Cheltenham, UK: Edward Elgar Publishing, 2017.

ORGANIZAÇÃO DAS NAÇÕES UNIDAS. Convenção-Quadro das Nacões Unidas sobre Mudança do Clima. 1992. Disponível em: https://unfccc.int/resource/ docs/convkp/conveng.pdf. Acesso em: 15 jun. 2019.

ORGANIZAÇÃO DAS NAÇÕES UNIDAS. Protocolo de Quioto à Convenção-Quadro das Nações Unidas sobre Mudança do Clima. 1997. Disponível em: https://unfccc. int/resource/docs/convkp/kpeng.pdf. Acesso em: 15 jun. 2019.

ORGANIZAÇÃO INTERNACIONAL PARA AS MIGRAÇÕES. Migration in INDCs/NDCs. Suíça: IOM, 2016. Disponível em: https://environmentalmigration. iom.int. Acesso em: 24 jun. 2019.

ORGANIZAÇÃO INTERNACIONAL PARA AS MIGRAÇÕES. Migration, environment and climate change: Assessing the evidence. Suíça: IOM, 2009.

ORIENTAL REPUBLIC OF URUGUAY. First Nationally Determined Contribution to the Paris Agreement. 2017. Disponível em: https://www4.unfccc.int/sites/ NDCStaging/Pages/All.aspx. Acesso em: 25 jun. 2019.

PERU. Ley Marco sobre Cambio Climático. 2018. Disponível em: https://www.undp.org/... Acesso em: 05 jul. 2019.

RAMOS, Erika Pires. Refugiados, migrantes ou deslocados ambientais: uma abordagem inspirada na proteção do meio ambiente e nos direitos humanos. In: LEITE, José Rubens Morato (coord.). Manual de direito ambiental. São Paulo: Saraiva, 2015.

REPUBLIC OF SURINAME. Intended Nationally Determined Contribution Under UNFCCC. 2015. Disponível em: https://www4.unfccc.int/sites/NDCStaging/Pages/All.aspx. Acesso em: 25 jun. 2019. 
REPUBLICA BOLIVARIANA DE VENEZUELA. Contribuciones Previstas Nacionalmente Determinadas de la República Bolivariana de Venezuela para la lucha contra el Cambio Climático y sus efectos. 2015. Disponível em: https://www4.unfccc.int/sites/NDCStaging/Pages/ All.aspx. Acesso em: 25 jun. 2019.

REPÚBLICA DE NICARAGUA. Decreto para establecer la Politica Nacional de Mitigación y Adaptación al Cambio Climático y de creación del Sistema Nacional de Respuesta al Cambio Climático. 2019. Disponível em: http://legislacion.asamblea.gob.ni/. Acesso em: 05 jul. 2019.

REPÚBLICA DEL ECUADOR. Primera Contribución Determinada a Nivel Nacional para el Acuerdo de París bajo la Convención Marco de Naciones Unidas sobre Cambio Climático. 2019. Disponível em: https://www4.unfccc.int/sites/ NDCStaging/Pages/All.aspx. Acesso em: 20 ago. 2019.

REPÚBLICA ORIENTAL DEL URUGUAY. Politica Nacional de Cambio Climático. 2017. Disponível em: https://www.undp.org/... Acesso em: 05 jul. 2019.

REPUBLIQUE D’HAÏTI. Contribution Prévue Déterminée au niveau National. 2017. Disponível em: https://www4. unfccc.int/sites/NDCStaging/Pages/All.aspx Acesso em: 05 jul. 2019.

RIVERA, M. T. C. El cambio climático: análisis científico y jurídico del problema de la emisión de gases de efecto invernadero. Revista de Derecho Urbanistico y Medio Ambiente, v. 31, n. 156, p. 1209-1235, 1997.

$\mathrm{SAAD}$, Aaron. Climate change, compelled migration and global social justice. In: SANDBERG, L. Anders; SANDBERG, Tor (ed.). Climate change: Who's carrying the burden? The chilly climates of the global environmental dilemma. Ottawa, Canadá: Our School/Our Selves (OS/OS), 2010.

SANTA LUCIA. Department of Sustainable Development, Ministry of Education, Innovation, Gender Relations and Sustainable Development. Saint Lucia's National Adaption Plan: 2018-2028. 2018. Disponível em: https://www4.unfccc.int/sites/NAPC/Documents/ Parties/SLU-NAP-May-2018.pdf. Acesso em: 20 jun. 2019.

SILVA, Geraldo Eulálio do Nascimento e. Direito Internacional Ambiental. 2 ed. Rio de Janeiro: Thex, 2002.

UNITED NATIONS HIGH COMMISSIONER FOR REFUGEES. A Toolbox: planning relocations to protect people from disasters and environmental changes.
Suíça: UNHCR e IOM, 2015.

UNITED NATIONS. Convenção-Quadro das Nacões Unidas sobre Mudança Climática. 2015. Disponível em: http:/ / www.br.undp.org/content/dam/brazil/docs/ODS/.... Acesso em: 15 jun. 2019.

UNITED NATIONS. NDC Registry. Disponível em: https://www4.unfccc.int/sites/NDCStaging/Pages/ All.aspx. Acesso em: 20 jun. 2019.

UNITED NATIONS. Report of the Conference of the Parties on its Eighteenth Session, held in Doha from 26 November to 8 December 2012. 2013. Disponível em: http://unfccc. int/resource/docs/2012/cop18/eng/08a01.pdf. Acesso em: 10 jan. 2019.

UNITED NATIONS. Report of the Conference of the Parties on its Nineteenth Session. 2014. Disponível em: http:// unfccc.int/resource/docs/2013/cop19/eng/10a01. pdf. Acesso em: 15 jun. 2019.

UNITED NATIONS. Report of the Conference of the Parties on its sixteenth Session, held in Cancun from 29 November to 10 December 2010. Disponível em: http:/ / unfccc.int/ resource/docs/2010/ cop16/eng/07a01.pdf. Acesso em: 10 jan. 2019.

UNITED NATIONS. Report of the Conference of the Parties on its twenty-first Session: held in Paris from 30 November to 13 December 2015. Disponível em: http:/ / unfccc.int/ resource/docs/2015/cop21/eng/10a01.pdf. Acesso em: 10 jun. 2019.

UNITED NATIONS. Report of the Task Force on Displacement. 2018. Disponível em: https://unfccc.int/sites/ default/files/resource/2018_TFD_report_17_Sep.pdf. Acesso em: 10 jan. 2018.

UNITED NATIONS. Task Force on Displacement at a glance. 2017. Disponível em: https://unfccc.int/sites/ default/files/resource/TFD_brochure.pdf. Acesso em: 10 jun. 2019.

VIÑUALES, Jorge E. El régimen jurídico internacional relativo al cambio climático: perspectivas y prospectivas. Disponível em: http://www.oas.org/ Acesso em: 15 dez. 2018.

WARNER, Koko et al. Integrating human mobility issues within National Adaptation Plans. Policy Brief, n. 9, jun. 2014. Disponível em: http://collections.unu.edu/ eserv/UNU:1838/pdf11800.pdf. Acesso em: 01 jul. 2019. 
WARNER, Koko et al. National adaptation plans and YAMAMOTO, Lilian et al. Human mobility in the conhuman mobility. FMR Review, n. 49, maio 2015. Di- text of climate change and disasters: a South American sponível em: https://www.fmreview.org/sites/fmr/fi- approach. International Journal of Climate Change Strategies les/FMRdownloads/en/climatechange-disasters/war- and Management, v. 10, n. 1, p. 65-85, 2018. ner-kaelin-martin-nassef.pdf Acesso em: 01 jul. 2019. 
Para publicar na Revista de Direito Internacional, acesse o endereço eletrônico www.rdi.uniceub.br ou www.brazilianjournal.org.

Observe as normas de publicação, para facilitar e agilizar o trabalho de edição. 